\title{
UNIVERSIDAD JOSÉ CARLOS MARIÁTEGUI
}

VICERRECTORADO DE INVESTIGACIÓN

ESCUELA DE POSGRADO

SEGUNDA ESPECIALIDAD EN INGENIERÍA AMBIENTAL

TRABAJO ACADÉMICO

ANÁLISIS ESPACIO TEMPORAL DE CAMBIOS DE USO Y COBERTURA DE LA TIERRA EN LA CIUDAD DE

MOQUEGUA Y EL PUEBLO DE SAMEGUA

DE 1955 Y 2018

PRESENTADO POR

OSMAR CUENTAS TOLEDO

ASESOR

DR. EDGAR VIRGILIO BEDOYA JUSTO

PARA OPTAR TÍTULO DE SEGUNDA ESPECIALIDAD EN

INGENIERÍA AMBIENTAL

MOQUEGUA - PERÚ

2019 


\section{RESUMEN}

Las actividades antrópicas y los procesos de urbanización de las ciudades con el recorrer del tiempo, han intensificado los cambios de uso y cobertura de la tierra aceleradamente, ocasionando diversos impactos ambientales percibidos en los informes, mesas de trabajo e investigaciones locales, nacionales e internacionales. Los estudios de cambios de uso y cobertura de la tierra son imprescindibles para comprender los procesos de cambios naturales y antrópicos, además de analizar integralmente el medio ambiente y la sociedad, constituyéndose en la actualidad una importante herramienta de orientación para la toma de decisión en el ordenamiento territorial y ambiental. El objetivo del presente estudio es analizar el espacio temporal de cambios de uso y cobertura de la tierra en la ciudad de Moquegua y el pueblo de Samegua de 1955 y 2018, emplazadas en una zona de 13 200 hectáreas, utilizando técnicas de geoprocesamiento y análisis espacial, con información tecnológica de percepción remota diferente en cada año, para 1955 se utilizó aerofotografías y para el 2018 se utilizó imágenes satelitales de Google Earth, con la finalidad de cartografiar cinco categorías de uso y cobertura de la tierra identificadas de acuerdo a la metodología Corine Land Cover adaptada por el Ministerio del Ambiente del Perú; para detectar los cambios de uso y cobertura de la tierra fue aplicando la metodología de la matriz de tabulación cruzada, identificando que la categoría que tuvo gran disminución es "Sin/Poca Vegetación" con 3882,59 hectáreas con una tasa de variación de $-0,57$ \% por año, la categoría de "Cuerpo Agua" disminuyo 126,88 \% con una tasa de variación de -0,62 \%, y la categoría de "Yacimiento Arqueológico" disminuyo 59,88 hectáreas con una tasa de variación $-0,35 \%$ por año y la categoría que tuvo gran aumento es "Zona 
Agrícola" con 2 469,72 hectáreas con una tasa de variación de 1,93 \% por año, seguida por la categoría "Superficie Artificial” que aumento 1 835,12 hectáreas con la tasa de variación más alta de 30,53 \% por año.

Palabras clave: análisis espacio temporal, uso y cobertura de la tierra, geoprocesamiento, percepción remota, sistemas de información geográfica. 


\section{ÍNDICE DE CONTENIDO}

Pág.

Carátula

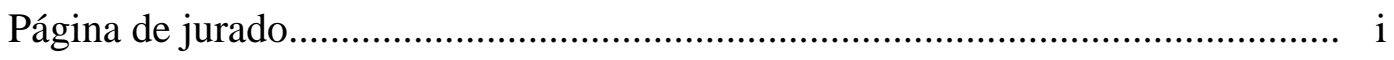

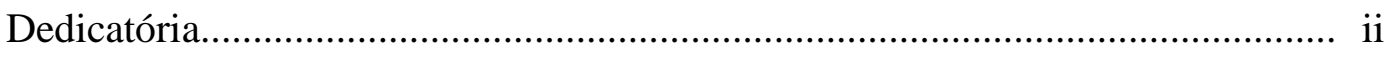

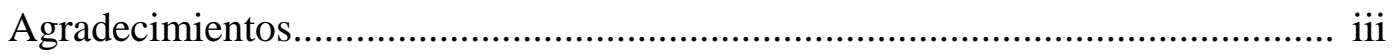

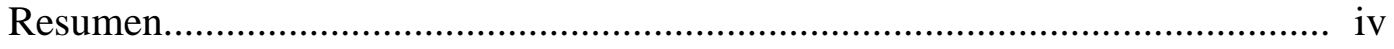

Índice de contenido.............................................................................. vi

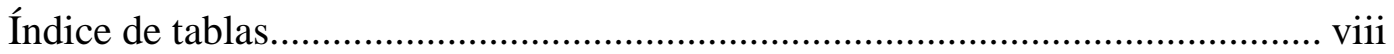

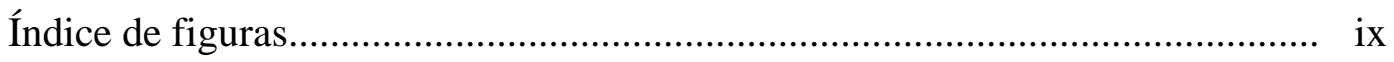

\section{CAPÍTULO I}

INTRODUCCIÓN

1.1. Antecedentes. 1

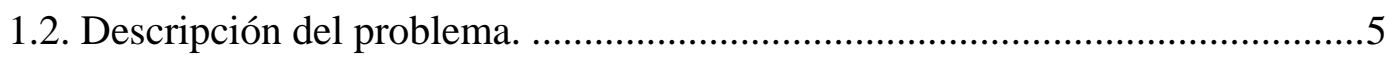

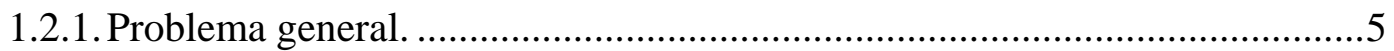

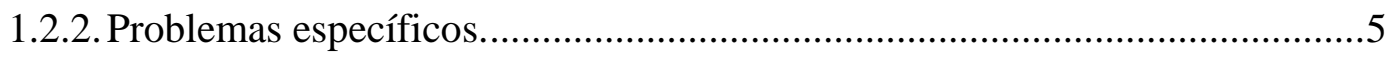

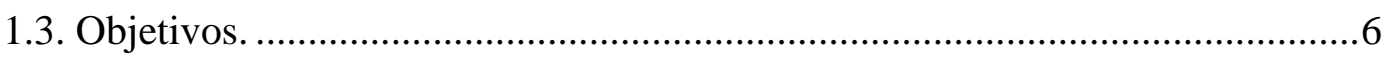

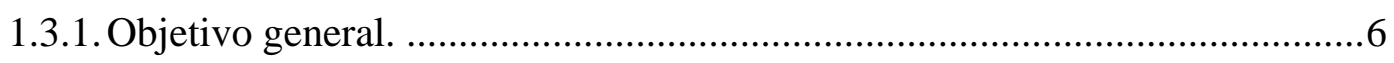

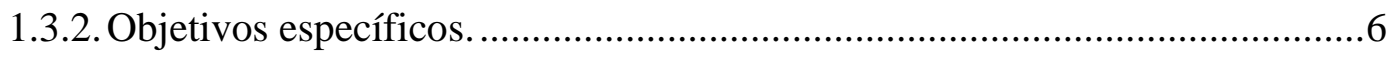

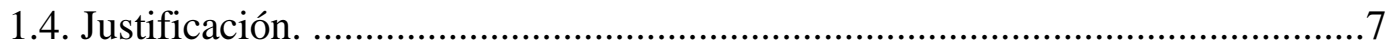

\section{CAPÍTULO II \\ DESARROLLO TEMÁTICO}

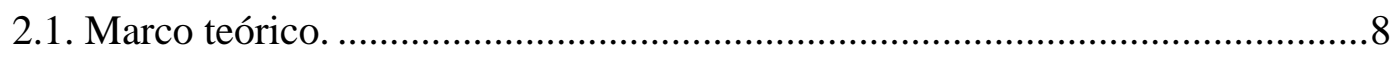

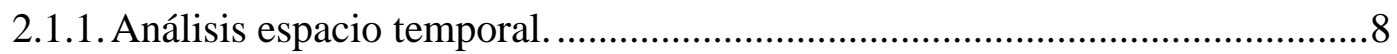

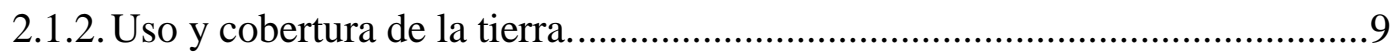

2.1.3. Sistemas de clasificación de uso y cobertura de la tierra.............................11

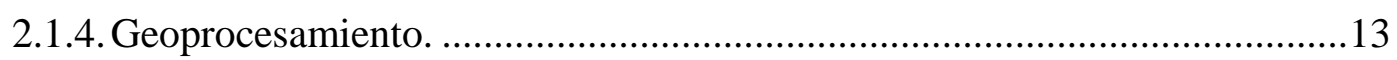

2.1.5. Cartografia para Geoprocesamiento. ..................................................... 14

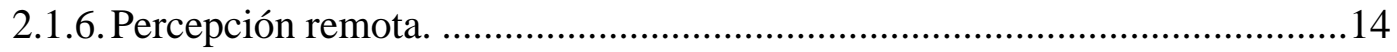

2.1.7. Sistemas de información geográfica.......................................................21 


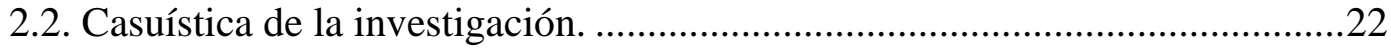

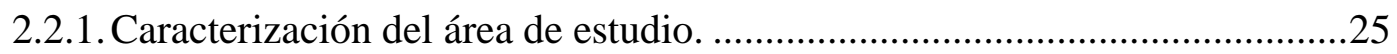

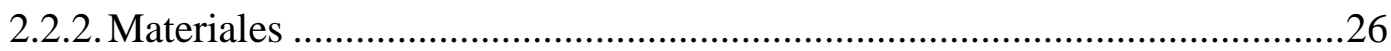

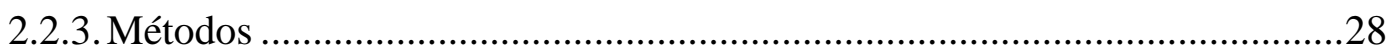

2.3. Presentación y discusión de resultados ........................................................44

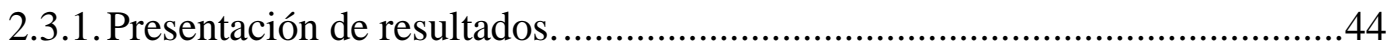

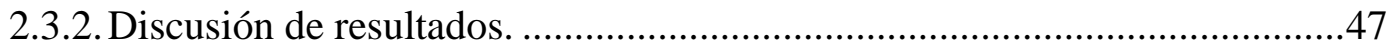

\section{CAPÍTULO III}

CONCLUSIONES Y RECOMENDACIONES

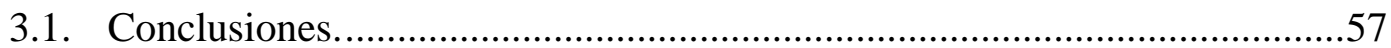

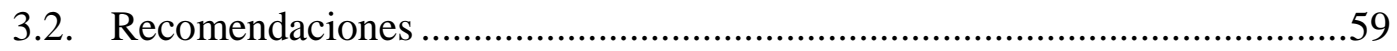

$\begin{array}{ll}\text { REFERENCIAS BIBLIOGRÁFICAS } & 60\end{array}$ 


\section{ÍNDICE DE TABLAS}

Pág.

Tabla 1 Categorías de la Clasificación Corine Land Cover

Tabla 2 Categorías de la Clasificación Corine Land Cover modificada para el análisis de uso y cobertura de la tierra entre los años de 1955 y 2018 de área de estudio. 30

Tabla 3 Matriz de tabulación cruzada general para comparar dos mapas de diferentes puntos en el tiempo

Tabla 4 Cambios totales de uso y cobertura de la tierra de la ciudad de Moquegua y el pueblo de Samegua entre 1955 y 2018. 47

Tabla 5 Categorías de uso y cobertura de la tierra de la ciudad de Moquegua y el pueblo de Samegua de 1955 49

Tabla 6 Categorías de uso y cobertura de la tierra de la ciudad de Moquegua y el pueblo de Samegua de 2018. 50

Tabla 7 Análisis de cambios de uso y cobertura de la tierra de la ciudad de Moquegua y el pueblo de Samegua entre 1955 y 2018 53

Tabla 8 Evolución y tasa de variación de uso y cobertura de la tierra de la ciudad de Moquegua y el pueblo de Samegua de 1955 al 2018 54

Tabla 9 Matriz de tabulación cruzada general de uso y cobertura de la tierra de la ciudad de Moquegua y el pueblo de Samegua de 1955 y 2018 56

Tabla 10 Síntesis de uso y cobertura de la tierra de la ciudad de Moquegua y el pueblo de Samegua de 1955 y 2018. 56 


\section{ÍNDICE DE FIGURAS}

Pág.

Figura 1. Procesos para adquirir información en la teledetección 15

Figura 2. Geometría de una foto aérea vertical 19

Figura 3. Vista panorámica de las viviendas de la ciudad de Moquegua de 1950.23

Figura 4. Vista del CEI de San Antonio que colapsó en el 2001. 23

Figura 5. Vista de la entrada de huayco en la Quebrada el Cementerio. 24

Figura 6. Mapa del área de estudio de la ciudad de Moquegua y el pueblo de Samegua. 26

Figura 7. Mosaico de fotografías aéreas de la zona de estudio. 27

Figura 8. Imágenes de alta resolución de Google Earth Pro. 28

Figura 9. Alineación de la aerofotografía 710 con puntos de control. 32

Figura 10. Transformación de la aerofotografía por el método 1st Order Polinomial (Affine) 33

Figura 11. Transformación de la aerofotografía por el método 2st Order Polinomial 33

Figura 12. Transformación de la aerofotografía por el método 3st Order Polinomial

Figura 13. Transformación de la aerofotografía por el método Ajust. 34

Figura 14. Transformación de la aerofotografía por el método Projective Transformation 34

Figura 15. Transformación de la aerofotografía por el método Spline 35

Figura 16. Transformación de la aerofotografía por el método Zero Order Polinomial (Shift) 35 
Figura 17. Vectorizado manual de la ciudad de Moquegua en 1955 38

Figura 18. Vectorizado de la cobertura vegetal del área de estudio 38

Figura 19. Construcción de base de datos para el uso y cobertura de la tierra de la ciudad de Moquegua y el pueblo de Samegua de 1955. 39

Figura 20. Software SAS,Planet para descargar imágenes desde google earth. ... 40

Figura 21. Software global Mapper para unir todas las imágenes de SAS.Planet. 40

Figura 22. Vectorizado manual de la ciudad de Moquegua y el pueblo de Samegua en 2018 . 41

Figura 23. Construcción de base de datos para el uso y cobertura de la tierra de la ciudad de Moquegua y el pueblo de Samegua del 2018 42

Figura 24. Cambios totales de uso y cobertura de la tierra de la ciudad de Moquegua y el pueblo de Samegua entre 1955 y 2018. 44

Figura 25. Mapa de uso y cobertura de la tierra de la ciudad de Moquegua y el pueblo de Samegua del año 1955. 45

Figura 26. Mapa de uso y cobertura de la tierra de la ciudad de Moquegua y el pueblo de Samegua del año 2018. 46

Figura 27. Mapa de cambios de uso y cobertura de la tierra de la ciudad de Moquegua y el pueblo de Samegua entre 1955 y 2018 47

Figura 28. Porcentaje de Cambios totales de uso y cobertura de la tierra de la ciudad de Moquegua y el pueblo de Samegua entre 1955 y 2018. 48

Figura 29. Categorías de uso y cobertura de la tierra de la ciudad de Moquegua y el pueblo de Samegua de 1955. 49

Figura 30. Categorías de uso y cobertura de la tierra de la ciudad de Moquegua y el pueblo de Samegua de 2018. 50 
Figura 31. Cambios de uso y cobertura de la tierra de la ciudad de Moquegua y el pueblo de Samegua de 1955 y 2018 ........ 55 


\section{CAPÍTULO I}

\section{INTRODUCCIÓN}

\subsection{Antecedentes.}

Los estudios especializados sobre cambios del uso y cobertura de la tierra de una área determinada son esenciales para proporcionar subsidios al monitoreo ambiental (Facco, Benedetti, Kaiser, \& Pereira, 2017), aplicado a dinámicas espacio-temporales del paisaje (Deng, Wang, Hong, \& Qi, 2009; Cabral \& Costa, 2017), expansión urbana (Sun, Crittenden, Li, Lu, \& Dou, 2018; Simwanda \& Murayama, 2018; Nkeki, 2016), expansión agrícola (Rukundo et al., 2018), sobreexplotación del recurso agua (G. Gao et al., 2018), destrucción de bosques (L. Gao et al., 2018), islas de calor urbano (Zhang et al., 2013), cambio climático (Woldesenbet, Elagib, Ribbe, \& Heinrich, 2018; A, Zhao, Qu, Jing, \& Xiong, 2016) entre otros estudios, convirtiéndose en un componente importante en las estrategias de planificación territorial, ordenamiento ambiental, conservación de la biodiversidad (Bonfim, Cordeiro, Peres, Canale, \& Bernardo, 2018; Mucova, Filho, Azeiteiro, \& Pereira, 2018; Nantel, Jones, \& Drake, 2018), gestión de áreas protegidas (Sahagún \& Reyes, 2017), planificación de energías renovables en áreas 
rurales (Poggi, Firmino, \& Amado, 2018) para alcanzar un desarrollo sostenible y dominar la dinámica expansiva del uso de la tierra (Bovet, Reese, \& Köck, 2018).

Los estudios sobre el uso y cobertura de la tierra en otros países están aumentando cada vez, ello por lograr realizar un ordenamiento territorial ambiental sostenible, innovándose nuevos métodos y técnicas para tal fin, las áreas que más se desarrollaron y continúan desarrollándose son las tecnologías de percepción remota y los sistemas de información geográfica, permitiéndonos obtener y procesar informaciones relacionadas al uso y cobertura de la tierra, de lugares inaccesibles y períodos de tiempos antiguos como actuales, contribuyendo en los procesos de toma de decisiones para planificar adecuadamente los recursos (Lao \& Peláez, 1988).

Todas las citas anteriores son de estudios realizados a nivel internacional, a nivel nacional existen pocos estudios sobre el uso y cobertura de la tierra, pero vemos que van aumentando, como lo refleja las búsquedas de información en internet, podemos citar algunos de ellos que se buscaron en Registro Nacional de Trabajos de Investigación para optar grados académicos y títulos profesionales (RENATI) de la Superintendencia Nacional de Educación Superior Universitaria (SUNEDU):

El estudio de cambio de cobertura del bosque tropical estacionalmente seco (BTES) de la cuenca Amojú - Jaén utilizando imágenes satelitales, periodo 2001 2013 aplica la metodología de clasificación Corine Land Cover (CLC), utiliza imágenes satelitales Landsat con modelos digitales de elevación y aplica las técnicas de segmentación y clasificación supervisada por el método de Random 
Forest, identificando 3 clases de cobertura y uso de la tierra; bosque abierto bajo 4561,8 ha $(10,68 \%)$, arbustal 324,8 ha $(0,76 \%)$ y vegetación arbustiva / herbácea 11679,3 ha (27,33\%), en la que la deforestación del área de estudio fueron de 179,4 ha/año (Oblitas, 2018).

En el estudio del análisis de la cobertura y uso de la tierra utilizando imágenes de resolución espacial media para el distrito de San Ramón Chanchamayo - Junín - Perú, se utiliza imágenes Landsat 8 del 2016 para su determinación, cuantificación y visualización, empleando el algoritmo Random Forest, con el 97,2\% de confiabilidad. Se clasifico por medio de la metodología CORINE Land Cover hasta el tercer nivel con 13 clases; también se utilizó el software ENVI EX para segmentar la imagen. El mapa resultante tuvo una consistencia de 95,33 \% de precisión con un índice Kappa de 0,922 (Gamarra, 2017).

El estudio sobre el análisis de cambio de cobertura y uso actual de la tierra con imágenes satelitales del distrito de Llacanaora periodo 2001 - 2016, genera información básica y analiza los cambios de cobertura y uso de la tierra por medio de imágenes LANDSAT con el uso de la metodología CORINE Land Cover identificando nueve coberturas; para el 2001 la cobertura que predomina son los cultivos transitorios que ocupa una superficie de 2 135,35 ha $(41,69 \%)$ y la cobertura con menor superficie es Tejido urbano continuo con 1,56 ha $(0,03 \%)$ de la área total en estudio. Para el periodo del 2016 la cobertura que predomina son Cultivos transitorios que ocupa una superficie de 2073,73 ha $(40,48 \%)$ y la 
cobertura de menor área es Laguna con una superficie de 19,17 (0,37 \%) (Murillo, 2018).

En el estudio análisis de cambio de cobertura y uso de tierra del distrito Chetilla, periodo 1990-2003-2016 se generó información primordial para el análisis de cambios de la cobertura y uso de la tierra desde imágenes LANDSAT, verificando en campo y corregir los polígonos. Se utilizó el sistema de clasificación CORINE Land Cover hasta el nivel III, para ser representada cartográficamente a escala 1/50000, por medio de la clasificación supervisada con Random Forest, logrando identificar las categorías: Tejido urbano continuo, Pastos, Áreas agrícolas heterogéneas, Bosques plantados, Herbazal, Arbustal, Afloramiento rocoso y Áreas quemadas. Los cambios de mayor área del 2003-2016, es la categoría de áreas agrícolas heterogéneas de 1 483,38 (ha) a 1 997,04 (ha), aumentando 513,67 (ha), Los cambios de mayor área del 1990-2016, es la categoría de áreas agrícolas heterogéneas de 744,25 (ha) a 1 997,04 (ha), aumentando 1 252,79 (ha) (Vilchez, 2018).

En el Perú el "Estudio de análisis de los cambios de la cobertura y uso de la tierra", es un instrumento técnico sustentatorio del ordenamiento territorial denominado "Estudio Especializado" (EE) incorporado desde el 2013, en la que se aprueba la “Guía Metodológica para la Elaboración de los Instrumentos Técnicos Sustentatorios para el Ordenamiento Territorial" (R.M. N 135-2013-MINAM, 2013), los EE componen la información base para la elaboración de la Zonificación Económica Ecológica (ZEE) en la temática de la dinámica del territorio, los mismos que contribuyen a lograr el Diagnóstico Integrado del Territorio (DIT) para 
finalmente elaborar el plan de ordenamiento Territorial (POT) (Arnillas et al., 2014). Para los estudios actuales se realizan de acuerdo a (R.M. N 081-2016MINAM, 2016).

En el departamento de Moquegua el 29 de agosto del 2018 “Aprueban el Reglamento Interno de la Comisión Técnica Regional de Zonificación Ecológica y Económica de la Región Moquegua”, donde se establecerán la organización, estructura y funcionamiento de la Comisión Tecnica Regional (D.R. № 002-2018GR/MOQ, 2018).

Los estudios de la dinámica de uso y cobertura de la tierra en la cuenca hidrográfica alta del Rio Moquegua entre los año de 1973 y 2016, identifican que existió crecimiento de las áreas urbanas de 14 veces, aumento de áreas de minería metálica y no metálica en 1 092,77 ha y disminución de coberturas de glaciares en 93,3\% junto a las coberturas de bofedal que disminuyeron en $24,87 \%$ (Cuentas, 2017).

\subsection{Descripción del problema.}

Por lo mencionado anteriormente se plantea las siguientes interrogantes:

\subsubsection{Problema general.}

¿Cuál será el espacio temporal de cambios de uso y cobertura de la tierra en la ciudad de Moquegua y el pueblo de Samegua entre 1955 y $2018 ?$

\subsubsection{Problemas específicos.}

¿Qué categorías y distribuciones espaciales de uso y cobertura de la tierra existen en la ciudad de Moquegua y el pueblo de Samegua para el año de 1955? 
¿Qué categorías y distribuciones espaciales de uso y cobertura de la tierra existen en la ciudad de Moquegua y el pueblo de Samegua para el año de 2018?

¿Cuáles son las áreas de cambio respecto a las categorías y distribución espacial del uso y cobertura de la tierra en la ciudad de Moquegua y el pueblo de Samegua entre 1955 у $2018 ?$

\subsection{Objetivos.}

Los objetivos se describen a continuación:

\subsubsection{Objetivo general.}

Analizar el espacio temporal de cambios de uso y cobertura de la tierra en la ciudad de Moquegua y el pueblo de Samegua de 1955 y 2018.

\subsubsection{Objetivos específicos.}

Identificar y cartografiar las categorías y distribución espacial del uso y cobertura de la tierra en la ciudad de Moquegua y el pueblo de Samegua de 1955 a partir de fotografías aéreas.

Identificar y cartografiar las categorías y distribución espacial del uso y cobertura de la tierra en la ciudad de Moquegua y el pueblo de Samegua de 2018 a partir de imágenes satelitales de Google Earth.

Cartografiar y analizar las áreas de cambio de uso y cobertura de la tierra en la ciudad de Moquegua y el pueblo de Samegua entre 1955 y 2018 con técnicas de geoprocesamiento. 


\subsection{Justificación.}

Las investigaciones sobre los cambios de uso y cobertura de la tierra en la ciudad de Moquegua y el pueblo de Samegua, son estudios esenciales para la planificación del desarrollo integral, ordenado y sostenible de las mismas. Permitiendo identificar y determinar los problemas de ordenamiento territorial ambiental que posee estas ciudades en sus diferentes sectores, apoyados en el uso de técnicas de geopreocesamiento, fotogrametría, teledetección y sistemas de información geográfica hasta para obtener información espacial y temporal.

La investigación será útil para los tomadores de decisión ${ }^{1}$ y planificadores de la gestión del ordenamiento territorial ambiental, que formen parte de instituciones públicas o privadas localizadas en el ámbito local, regional y nacional; también será aplicado en temas de interés como urbano, rural, agrícola, arqueológico, minero, forestal, prevención y mitigación de desastres entre otros.

La aplicación de esta metodología será útil para la sociedad, será una guía básica para aplicar en otras localidades, regiones y países que tienen la necesidad de mapear y evaluar los cambios de uso y cobertura de la tierra.

En el ámbito académico permite conocer y aplicar metodologías de geoprocesamiento y sistemas de información geográfica.

\footnotetext{
1 "Se refiere a aquellos cuyas acciones dependen de o afectan los servicios ecosistémicos" (Patiño \& Tobasura, 2011).
} 


\section{CAPÍTULO II}

\section{DESARROLLO TEMÁTICO}

\subsection{Marco teórico.}

\subsubsection{Análisis espacio temporal.}

El concepto sobre análisis espacio-tiempo es para profundizar en cantidades masivas de datos espaciotemporales y obtener una comprensión de la dinámica espacial, si bien no existe una definición unificada, la analítica se define aquí como la ciencia o el método de examinar algo complejo para determinar su naturaleza, estructura o características esenciales. La analítica del espacio-tiempo extiende la definición de la analítica al uso del espacio y el tiempo como marcos de procesamiento, extracción, visualización, comprensión y comunicación para simplificar la complejidad de la dinámica espacial en elementos y estructuras en el espacio y el tiempo. Debido a que cada objeto o proceso existe en algún espacio y tiempo, los datos que proporcionan medidas de objetos espaciales o procesos espaciales deben tener referencias de ubicación y tiempo. Por lo tanto, el espaciotiempo sirve naturalmente como un marco común para la integración de datos; sin embargo, los datos son estáticos, las observaciones o muestras se toman en un lugar 
e instancia específicos. La analítica del espacio-tiempo apunta no solo a descubrir patrones de propiedades capturadas por los datos, sino también a revelar los procesos subyacentes que impulsan los patrones (Yuan \& Bothwell, 2013).

\subsubsection{Uso y cobertura de la tierra.}

Revisando las investigaciones sobre estudios de cambio de uso y cobertura de la tierra no utilizan definiciones similares de los términos principales tierra, uso de la tierra, cobertura de la tierra y cambio de uso de la tierra. La definición y descripción que brindan los investigadores de estos términos varían con respecto al propósito de aplicarlos (Briassoulis, 2000). Por lo que es conveniente esclarecer por separado los términos de tierra, uso de la tierra, cobertura de la tierra, cambios de uso de la tierra, los que se citan a continuación.

\subsubsection{Tierra.}

El concepto de tierra fue descripto por la Organización de las Naciones Unidas para la Agricultura y la Alimentación (FAO) en el año de 1995 (FAO, 1995) (FAO, 2001), tal como sigue:

"La tierra es un área delineable de la superficie terrestre de la Tierra, que abarca todos los atributos de la biosfera inmediatamente por encima o por debajo de esta superficie, incluidos los del clima cercano a la superficie que forman el suelo y el terreno, la hidrología de la superficie (incluidos los lagos poco profundos, ríos, pantanos y pantanos), las capas sedimentarias cercanas a la superficie y la reserva de agua subterránea asociada, las poblaciones de plantas y animales, el patrón de asentamiento humano y los 
resultados físicos de la actividad humana pasada y presente (terrazas, almacenamiento de agua o estructuras de drenaje, carreteras, edificios, etc)".

Cabe resaltar que Tierra escrito con mayúscula se refiere al planeta Tierra. El termino tierra significa el sistema bioproductivo terrestre que comprende el suelo, la vegetación, otra biota y los procesos ecológicos e hidrológicos que operan dentro del sistema (United Nations General Assembly, 1994).

\subsubsection{Uso de la tierra.}

El uso de la tierra se relaciona con la forma en que es utilizada por la población humana local (Lambin, Rounsevell, \& Geist, 2000). Está compuesto por actividades antrópicas relacionadas con un área de tierra, con la intención de obtener productos y beneficios a través del uso de recursos. En otras palabras, se relaciona con funciones socioeconómicas, por ejemplo, agricultura, vivienda, áreas de protección ambiental, entre otras (Commisison européenne, 1994) (Macedo et al., 2018). El uso de la tierra incluye aspectos más allá de la caracterización de la cobertura biofísica de la tierra (Batista, 2011).

El uso de la tierra implica tanto la manera en que se manipulan los atributos biofísicos de la tierra como la intención subyacente a esa manipulación, el propósito para el cual se usa la tierra (Turner II et al., 1995). El uso de la tierra se refiere a los propósitos para los cuales los humanos explotan la cobertura de la tierra. Los usos comunes de la tierra incluyen la agricultura, el pastoreo, la silvicultura, la extracción de minerales y la recreación (Servicio Nacional de Meteorologia e Hidrologia del Perú - SENAMHI, 2010). 


\subsubsection{Cobertura de la tierra.}

El término cobertura de la tierra se refiere a los atributos de una parte de la superficie terrestre de la Tierra y del subsuelo inmediato, incluidos la biota, el suelo, la topografía, las aguas superficiales y subterráneas y las estructuras humanas. La cobertura de la tierra se puede clasificar de acuerdo con numerosos criterios, dependiendo de los propósitos científicos para los cuales se está desarrollando la clasificación. Ejemplos de algunas categorías amplias de cobertura de tierras incluyen bosques boreales, sabanas tropicales, pastizales templados, tierras de cultivo, humedales y asentamientos (Turner II, Ross, \& Skole, 1993).

\subsubsection{Cambios de uso y cobertura de la tierra.}

En el análisis del uso de la tierra y el cambio de la cobertura terrestre, primero es necesario conceptualizar el significado del cambio para detectarlo en situaciones del mundo real. A un nivel muy elemental, el uso de la tierra y el cambio en la cobertura de la tierra significa cambios (cuantitativos) en la extensión del área (aumentos o disminuciones) de un tipo dado de uso de la tierra o cobertura de la tierra, respectivamente. Es importante tener en cuenta que, incluso en este nivel, la detección y medición del cambio depende de la escala espacial; cuanto más alto sea el nivel espacial de detalle, mayores serán los cambios en la extensión del área de uso y cobertura del suelo que pueden detectarse y registrarse (Briassoulis, 2000).

\subsubsection{Sistemas de clasificación de uso y cobertura de la tierra.}

Para mapear las coberturas de la tierra en distintos países de Latinoamérica se han logrado por medio de diferentes sistemas de clasificación, fuentes de información, 
escalas y métodos para procesar múltiples informaciones de datos e imágenes. Así se puede citar que en Colombia, el mapa nacional de coberturas de la tierra se elaboró con la metodología adaptada de Corine Land Cover - CLC de la Unión Europea; en Argentina se utilizó el Land Cover Classification System - LCCS de la Organización de las Naciones Unidas para la Alimentación y la Agricultura (FAO) (Posada \& Salvatierra, 2016).

\subsubsection{Corine Land Cover (CLC)}

El inventario CORINE Land Cover (CLC) se inició en 1985 (año de referencia 1990). Las actualizaciones se produjeron en 2000, 2006 y 2012. Consiste en un inventario de la cobertura del suelo en 44 clases. CLC utiliza una Unidad de Mapeo Mínimo (MMU) de 25 hectáreas (ha) para fenómenos de área y un ancho mínimo de 100 m para fenómenos lineales. Las series de tiempo se complementan con capas de cambio, que resaltan los cambios en la cobertura del suelo con una MMU de 5 ha. Las MMU diferentes significan que la capa de cambio tiene una resolución más alta que la capa de estado. Debido a las diferencias en las MMU, la diferencia entre dos capas de estado no será igual a la correspondiente capa de cambios CLC (CORINE Land Cover, 2018).

\subsubsection{Land Cover Clasification System (LCCS)}

El Sistema de Clasificación de Cobertura Terrestre es realizado por la FAO para suministrar un marco coherente para clasificar y mapear la cobertura terrestre denominado en inglés Land Cover Classification System (LCCS), es un sistema de clasificación a priori completo y estandarizado, diseñado para cumplir con los requisitos específicos del usuario y creado para ejercicios de mapeo, 
independientemente de la escala o los medios utilizados para cartografiar. Cualquier cubierta de tierra identificada en cualquier parte del mundo se puede acomodar fácilmente. La clasificación utiliza un conjunto de criterios de diagnóstico independientes que permiten la correlación con las clasificaciones y leyendas existentes (Di Gregorio \& Jansen, 2000).

Las clases de cobertura terrestre son definidas por criterios de diagnóstico independiente, llamado clasificador, organizado jerárquicamente garantizando un gran valor de precisión geográfica. La cobertura terrestre es heterogénea, por lo que no se puede utilizar los mismos clasificadores para definir todos los tipos de cobertura de la tierra, por lo que esta clasificación tiene dos fases principales (Di Gregorio \& Jansen, 2000):

1. La fase dicotómica inicial, donde se distinguen ocho tipos principales de cobertura terrestre; y

2. La subsiguiente fase jerárquica modular donde el conjunto de clasificadores y su disposición jerárquica se adaptan al tipo principal de cobertura del suelo.

\subsubsection{Geoprocesamiento.}

El Geoprocesamiento, tecnología aplicada en el SIG, puede ser definido como el conjunto de técnicas y metodologías que implican en la adquisición, archivado, procesamiento y representación de datos georeferenciados (Buffara, 2018). El Geoprocesamiento es un término amplio, que engloba diversas tecnologías de tratamiento y manipulación de datos geográficos, a través de programas informáticos. Entre estas tecnologías, se destacan: la percepción remota, la digitalización de datos, la automatización de tareas cartográficas, la utilización de 
Sistemas de Posicionamiento Global - GPS y los Sistemas de Información Geográfica (SIG). Es decir, el SIG es una de las técnicas de geoprocesamiento, la más amplia de ellas, ya que puede englobar todas las demás, pero no todo el geoprocesamiento es un SIG (Pina \& Santos, 2018).

\subsubsection{Cartografía para geoprocesamiento.}

La cartografía es la disciplina relacionada con el arte, la ciencia y la tecnología de hacer y usar mapas (ICA, 2018).

La razón principal de la relación interdisciplinaria fuerte entre Cartografía y Geoprocesamiento es el espacio geográfico. La cartografía se preocupa en presentar un informe modelo de representación de datos para los procesos que ocurren en el espacio geográfico. Geoprocesamiento representa el área del conocimiento que utiliza técnicas matemáticas y computacionales, proporcionadas por los Sistemas de Información Geográfica (SIG), para tratar los procesos que ocurren en el espacio geográfico. Esto establece de forma clara la relación interdisciplinar entre Cartografía y Geoprocesamiento (Câmara, Davis, \& Vieira, 2018).

\subsubsection{Percepción remota.}

La percepción remota o teledetección espacial es la ciencia (y hasta cierto punto, el arte) que por medio de una serie de procesos se adquiere información de la superficie Terrestre sin estar en contacto físico con ella. Esto se hace detectando y registrando la energía reflejada o emitida y procesando, analizando y aplicando esa información (Natural Resources, 1999). 
Los procesos para adquirir información en la teledetección se muestran en la figura

1.

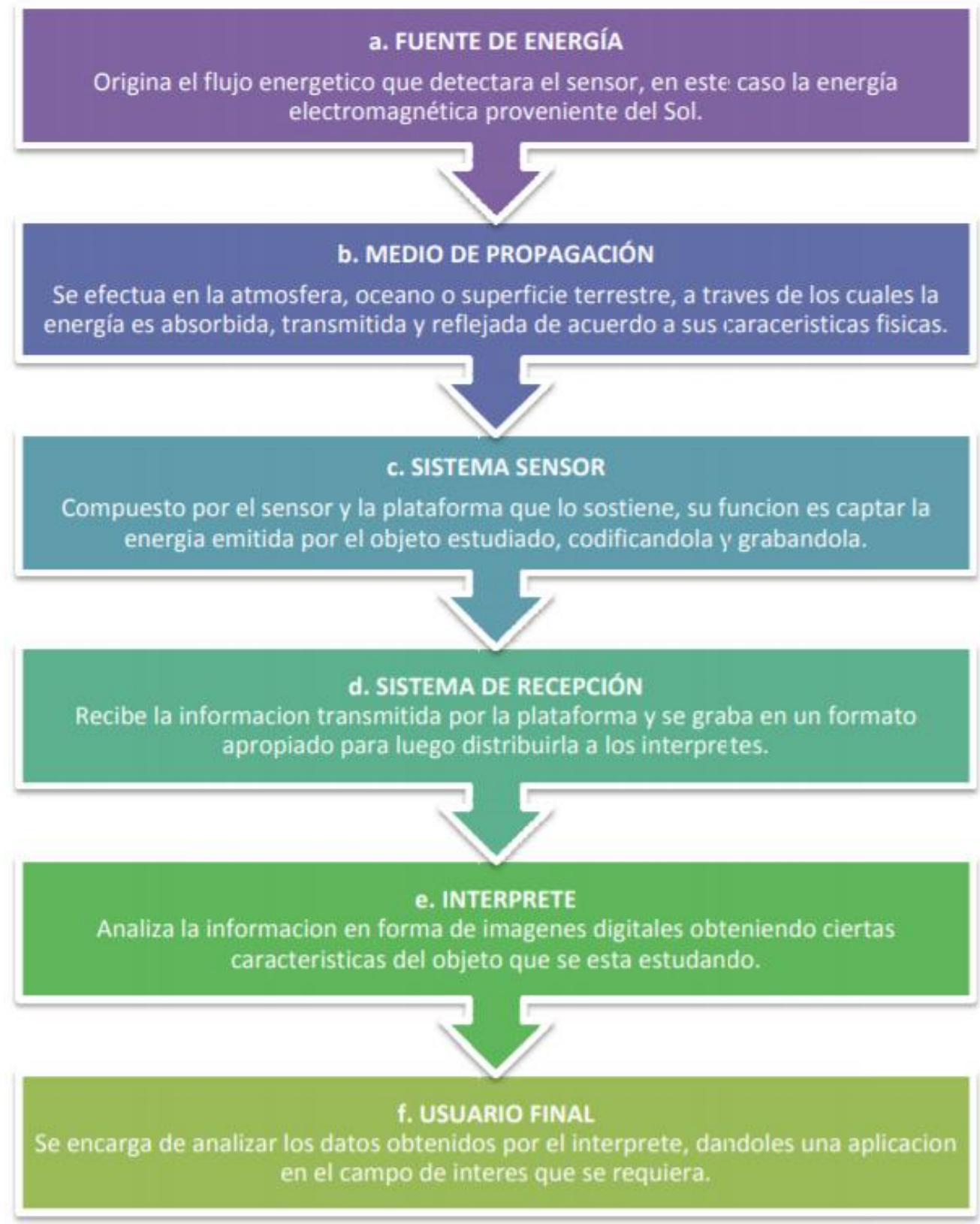

Figura 1. Procesos para adquirir información en la teledetección

Fuente: (Avalos, 2012).

En los trabajos que involucran los procesos de percepción remota o teledetección, en lo referente al análisis de datos se debe considerar dos etapas (Valentina \& Matar, 2016) : 
a) La obtención de datos o información;

b) El análisis o interpretación de esos datos.

Para desarrollar la etapa de obtención de datos, se dispone información de varios tipos de sensores, según la región del espectro electromagnético en que operan. En el presente trabajo nos ocuparemos en exclusivo de las fotografías aéreas pancromáticas y las imágenes de satélite de alta resolución.

El uso combinado de fotografías aéreas e imágenes satelitales demostró ser una herramienta altamente eficiente para la exploración de los archivos de paisajes. Algunas propiedades y posibilidades técnicas, tanto digitales como analógicas, crean nuevos puntos de vista y perspectivas para la investigación del paisaje (Daels, 1992).

\subsubsection{Fotografías aéreas.}

Las fotografías aéreas o aerofotografías son representaciones fidedignas de la superficie del terreno en el instante que se realizan la toma o exposición, contienen información relevante para varios estudios temáticos que tienen relación con las ciencias naturales. Las informaciones que se pueden obtener de las aerofotografías solamente se limitan por la capacidad de percepción del hombre al momento que realiza la interpretación de la fotografía aérea. Las clases de fotografía aérea según la escala son (INEGI, 2005):

- Escala 1:20 000 y 1:40 000 en blanco y negro para catastro rural.

- Escala 1:25 000 y 1:35 000 en color para fotointerpretación en recursos naturales. 
- Escala 1:50 000 en blanco y negro para elaborar cartas topográficas a escala 1:50 000.

- Escala 1:75000 para actualización de la carta topográfica 1:50 000.

- Escalas diversas de 1:2 500 a 1:15 000 en casos especiales para estudio y evaluación de zonas de desastre, catastro urbano y otros fines.

Existen cuatro métodos elementales para determinar la escala en la aerofotografía, que se indican a continuación ordenados progresivamente respecto a la exactitud (Butler, LeBlanc, Belbin, \& MacNeill, 1990):

1. Relacionando la distancia conocida entre dos puntos del terreno con la distancia entre mismos puntos en la aerofotografía. (Note que la escala puede variar para otros lugares sobre la misma aerofotografía, si hay variaciones significativas del relieve).

2. Relacionando distancias entre dos puntos del mapa y los mismos dos puntos en la aerofotografía.

3. Relacionando las dimensiones de un objeto en el terreno y las mismas dimensiones del objeto en la aerofotografía.

4. Relacionando la distancia focal de las lentes de la cámara con la altitud de las lentes de la cámara.

Las aerofotografías obtenidas desde un avión volando en líneas paralelas, llamadas líneas de vuelo. La planificación de vuelo generalmente garantiza que haya superposición de fotos para la cobertura del área estudiada. Las superposiciones ocurren lateralmente (en el orden del 15 al $40 \%$ ) y (en el orden del 55 al $65 \%$ ). Los terrenos accidentados exigen una superposición mayor, con la superposición adelante / atrás, una vista estereoscópica es posible, creando para el 
usuario una imagen tridimensional (Câmara, Casanova, Hemerly, Magalhães, \& Medeiros, 1996).

\section{Características de las fotos aéreas}

La geometría de las fotos aéreas están descritas por el tipo de proyección cónica, permitiendo determinar las siguientes características que también se muestra en la figura 2 (Valentina \& Matar, 2016):

a) Los puntos de control que se establecieron en el terreno son proyectados por el trazo de una línea sobre la película. De tal manera que cada punto de intersección en la línea serán los centros de perspectiva, las mismas que coinciden con el centro óptico del objetivo.

b) Respecto a las tomas verticales, los puntos centrales de cada foto aérea deberá coincidir con el nadir del terreno.

c) Considerando los recubrimientos longitudinales del $60 \%$ en cada foto aérea vertical e identificando sus puntos centrales en las dos fotografías vecinas y logrando unir estos tres puntos centrales por una línea podemos hallar la dirección o trayecto del vuelo.

d) Se debe identificar que la aero-base es la línea, que articula el nadir del terreno de tres fotos inmediatas. También identificar la foto-base refiriéndose a la línea, que articula los centros de fotografías aéreas vecinas. La aero-base y la foto-base coinciden sólo en fotos perfectamente verticales. 


\section{Geometría de una foto aérea vertical}

El centro de la foto vertical coincide con el nadir del terreno. Los centros de las fotos vecinas están transferidas a esta foto.

La fotobase une los centros de las fotos:

La línea, que une los nadires del terreno es la aerobase.

\section{SGriem-Klee, fotaer $2 b$.odt}

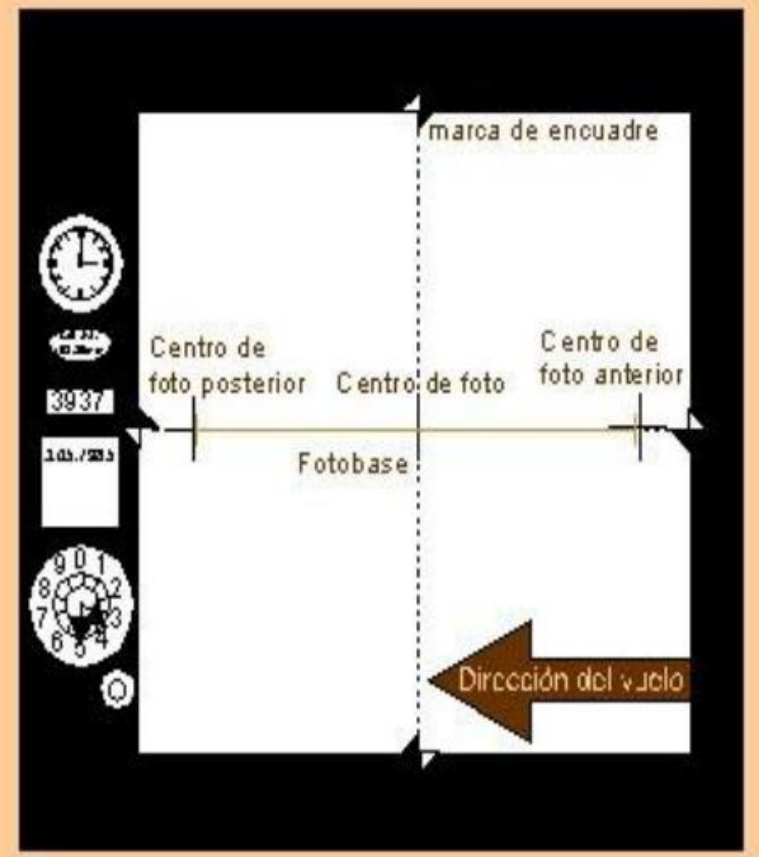

Figura 2. Geometría de una foto aérea vertical

Fuente: (Valentina \& Matar, 2016).

\section{Fotointerpretación}

Es un proceso por medio del cual se obtiene información contenida en la fotografía aérea; para este proceso primeramente se realiza un reconocimiento y ubicación de los diversos elementos que aparecen en la fotografía. Para un buen trabajo se requiere de conocimientos por especialistas para identificar los procesos geomorfológicos, formaciones geológicas, formaciones vegetales, usos y cobertura de la tierra del área en estudio; además se debe tener información de la escala del fotograma para deducir el tamaño de cada objeto capturado en la fotografía. (Valentina \& Matar, 2016). 


\subsubsection{Imagen de satélite.}

La imagen de satélite es la representación visual de datos de radiación reflejada por la superficie terrestre, formando un archivo de imagen obtenido por teledetección desde un sensor que va acoplado a un satélite artificial. Los datos que obtienen estos sensores son las mediciones de las radiaciones reflejadas por unidad de superficie para una banda (longitud de onda determinada), que se envían a una base terrena para ser procesados y convertirlos en imágenes. Estas imágenes están en formato ráster compuesta por una matriz regular o rejilla de celdas o cuadritos de un mismo tamaño, conocidas como píxel, al que se le asigna un valor digital correspondiendo a la intensidad de brillantes recogida por el sensor (León, 2002).

\section{Google Earth Pro}

Google Earth Pro es un programa informático y una herramienta elemental de investigación, presentación y colaboración para informarnos específicamente de un lugar del globo terrestre virtual, brinda información más completa de datos geoespaciales utilizables de modo público y gratuito, existiendo modalidades de pago para los que requieren información especializada, incluyen imágenes de alta resolución de calles, centros históricos, presentaciones de mapas 3D de algunas ciudades, mapas viales en detalle y lugares de interés importantes (Valentini, 2011; López et al., 2013). Una de las ventajas de utilizar Google Earth es que proporciona imágenes de satélite que tienen resolución espacial inferior a un metro, visualizando edificios, carreteras, cuerpos de agua entre otros. Facilitando la digitalización en pantalla en SIG para preparar el mapa de uso de la tierra (Malarvizhi, Kumar, \& Porchelvan, 2016). 


\subsubsection{Sistemas de información geográfica.}

El término Sistemas de Información Geográfica (SIG) es aplicado para sistemas que realizan el tratamiento computacional de datos geográficos y recuperan informaciones no sólo sobre la base de sus características alfanuméricas, sino también a través de su localización espacial; ofrecen al administrador (urbanista, planificador, ingeniero) una visión inédita de su ambiente de trabajo, en que toda la información disponible sobre un determinado asunto está a su alcance, interrelacionadas en base a lo que les es fundamentalmente común la ubicación geográfica. Para que esto sea posible, la geometría y los atributos de los datos en un SIG deben estar georreferenciados, es decir, ubicados en la superficie terrestre y representada en una proyección cartográfica (Câmara et al., 2018).

En resumen, las principales características de SIG's (Câmara et al., 1996) son:

- Integrar, en una única base de datos, información espacial procedente de datos cartográficos, datos de censo y registro urbano y rural, imágenes de satélite, redes y modelos numéricos de terreno.

- Combinar las diversas informaciones, a través de algoritmos de manipulación, para generar asignaciones derivadas.

- Consultar, recuperar, ver y trazar el contenido de la base de datos geocodificada.

Los datos tratados en SIG incluyen: imágenes de satélite, modelos numéricos de terreno, mapas temáticos, redes y datos tabulares. 


\subsection{Casuística de la investigación.}

La población del Departamento de Moquegua en 1940 era de 34152 habitantes y en el 2017 según los reportes de los Censos Nacionales 2017: XII de Población y VII de Vivienda fue de 174863 habitantes (INEI, 2018b), en el presente año la población proyectada a Junio del 2018 es de 186036 habitantes, según esta proyección la población de la ciudad de Moquegua y el pueblo de Samegua en el área de estudio que son las capitales de los distritos de Moquegua y Samegua son de 59572 y 6525 habitantes respectivamente (INEI, 2018a), con estos datos oficiales podemos indicar que las dos capitales de distritos casi duplican la población del Departamento Moquegua del año 1940, lo que induce a la existencia de cambios de uso y cobertura de la tierra en el desarrollo de la ciudad de Moquegua y el pueblo de Samegua.

El desarrollo de la ciudad de Moquegua y el pueblo de Samegua estuvieron en función de la agricultura, agroindustria y ganadería, desde los años de 1950 Moquegua y Samegua se situaron en la parte baja del valle localizándose en lugares donde el relieve es ligeramente plano, las casas construidas fueron de adobe y quincha como se observan en la figura 3. A partir de los años de 1960 con el crecimiento de la actividad agrícola y principalmente con el apogeo de la actividad minería estas ciudades se expandieron desordenadamente en dirección norte y sur principalmente, en la ciudad de Moquegua esta expansión fue en las laderas de los sectores El Siglo, San Francisco y Mariscal Nieto por la carencia de áreas adecuadas y cercanas a la ciudad de Moquegua; estos sectores fueron los más afectados durante el sismo que ocurrió el 23 de junio del 2001 donde diversos inmuebles 
colapsaron como se observa en la figura 4 (UNSA \& INDECI, 2001), este gran evento sísmico favoreció a consolidar la creación de los centros poblados de San Antonio y Chen Chen (MPMN, 2018).

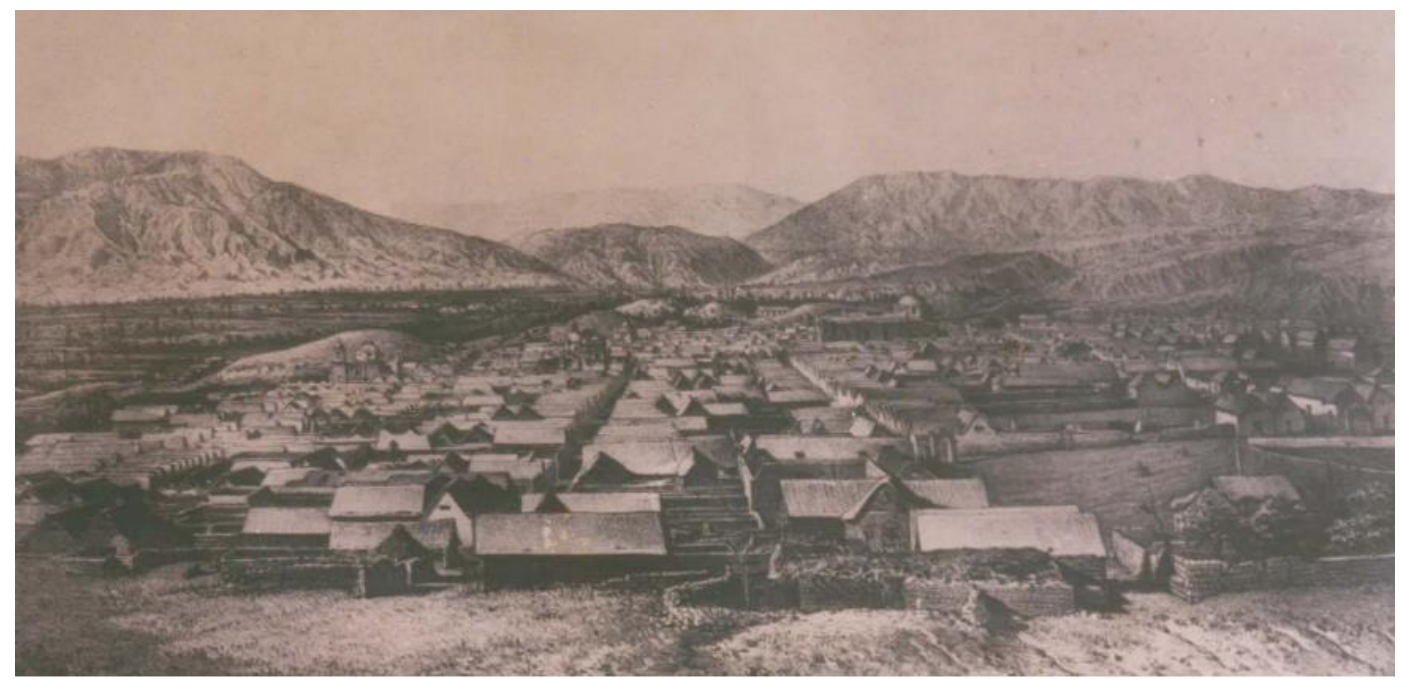

Figura 3. Vista panorámica de las viviendas de la ciudad de Moquegua de 1950.

Fuente: (UNSA \& INDECI, 2001).

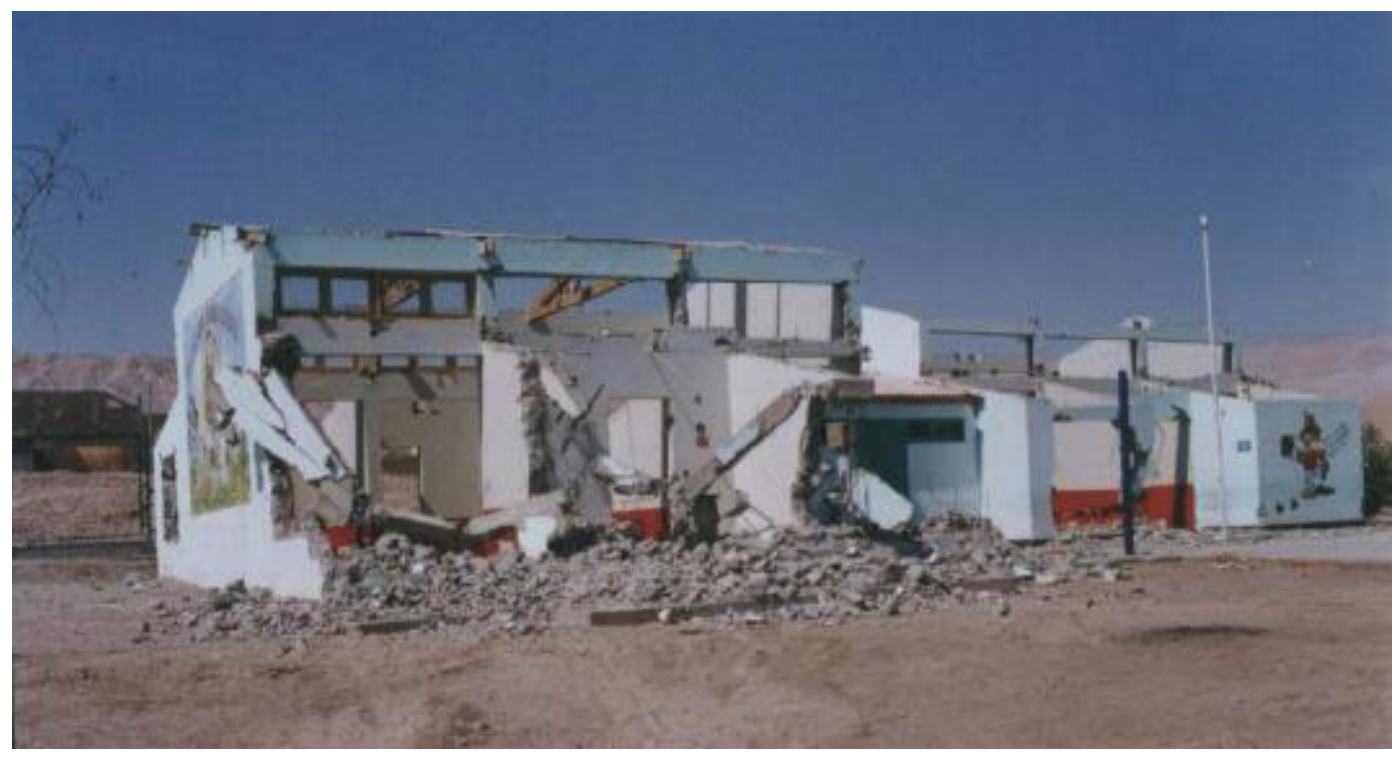

Figura 4. Vista del CEI de San Antonio que colapsó en el 2001.

Fuente: (UNSA \& INDECI, 2001).

La extensión de la población urbana continuará mostrando un incremento importante de la ciudad hacia terrenos eriazos y en muchos casos sobre áreas de 
riesgo por deslizamiento por sismos y/o inundaciones por efecto del cambio climático (MPMN, 2018), es un claro ejemplo la ocupación urbana en la “Quebrada del cementerio", recordando que en el año 2012 está quebrada se reactivó tras una gran precipitación donde se generaron flujos de detritos o huaicos afectando viviendas e infraestructuras en su recorrido como se observa en la figura 5 (Soncco \& Vela, 2018).

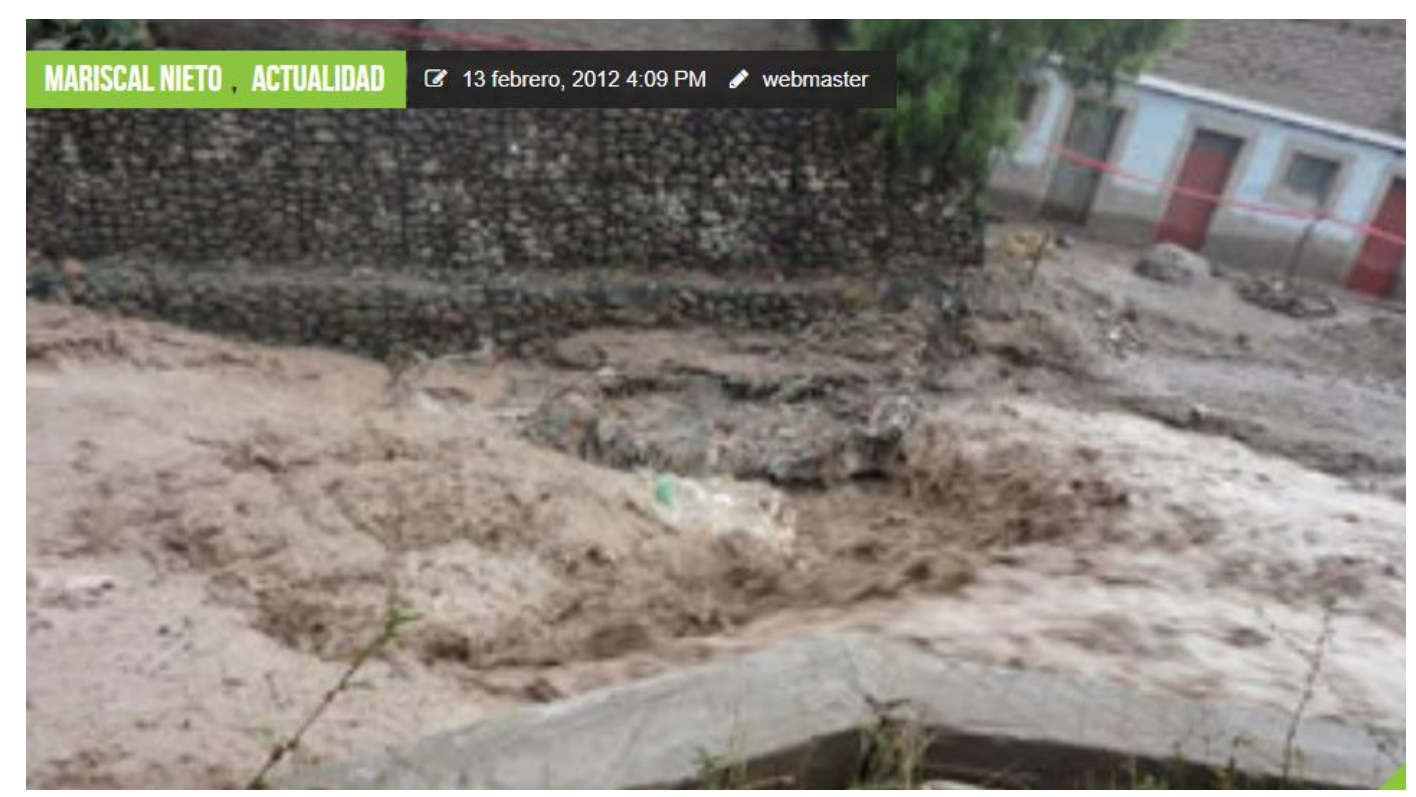

Figura 5. Vista de la entrada de huayco en la Quebrada el Cementerio.

Fuente: (Moquegua Noticias, 2012)

La mayor parte de problemas en lo referente al ordenamiento territorial ambiental, es el proceso de ocupación territorial urbana que se dieron en la ciudad de Moquegua y el pueblo de Samegua, son consecuencias de la carencia de una planificación urbana oportuna e integral, donde fueron rebasadas las construcciones informales y también se emplazaron en lugares no aptos para construir viviendas, motivo que es elemental que los gobiernos municipales implementen los documentos técnicos, legales y normativos para el control y planificación del 
desarrollo urbano apropiado con las normativas vigentes en armonía con la ocupación física ambiental actual (MPMN, 2016).

Por los estudios mencionados podemos indicar que el análisis espacio temporal de cambios de uso y cobertura de la tierra en la ciudad de Moquegua y el pueblo de Samegua de 1955 y 2018 que realizaremos, se constituirá en una importante herramienta y subsidio a la orientación y toma de decisión por las autoridades locales y regionales principalmente.

\subsubsection{Caracterización del área de estudio.}

El área de estudio ocupa la ciudad de Moquegua y el pueblo de Samegua que son las capitales de los Distritos de Moquegua y Samegua, ubicados en la Provincia Mariscal Nieto del Departamento de Moquegua, esta área ocupa 13200 hectáreas, de forma rectangular de 12000 metros en dirección Este y 11000 metros en dirección Norte, geodésicamente se encuentra en la zona 19 del hemisferio sur entre los 288000 a 300000 metros al Este y 8092000 a 8103000 metros al Norte del sistema geodésico mundial de 1984 en proyección Universal Transversa de Mercator, como se observa en la figura 6. 


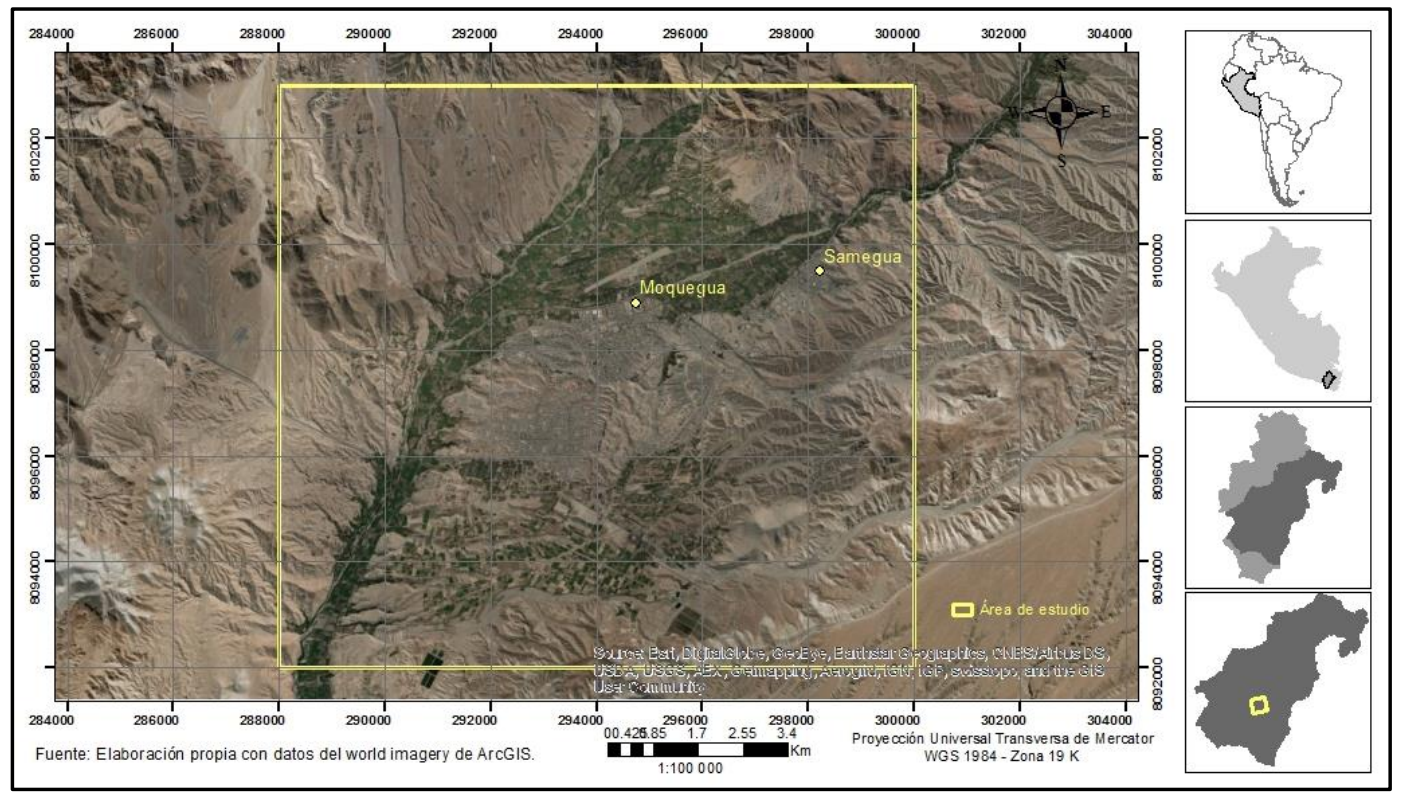

Figura 6. Mapa del área de estudio de la ciudad de Moquegua y el pueblo de Samegua.

Fuente: Elaboración propia con datos del World Imagery (ESRI, 2018).

La ciudad de Moquegua es la capital del Departamento de Moquegua, capital de la Provincia Mariscal Nieto y capital del Distrito de Moquegua, ubicada geográficamente a una altitud de $1428 \mathrm{msnm}, 70^{\circ} 55^{\prime} 60^{\prime \prime}$ longitud oeste y $17^{\circ} 11^{\prime} 39^{\prime \prime}$ latitud sur, fue creada en la época de la independencia. El pueblo de Samegua es la capital del distrito de Samegua, ubicado geográficamente a una altitud de 1615 msnm, 7054'01" longitud oeste, 17010'56" latitud sur, fue creada por ley S/N el 08 de noviembre de 1894 (INEI, 2018a), por Ley N 12301 Samegua al igual que todas las capitales de distritos cambia su categoría de caserío o pago por la de pueblo el 30 de abril de 1955 (Kuon, 1996).

\subsubsection{Materiales}

Para el presente trabajo se utilizó fotografías aéreas e imágenes de satélite de alta resolución de Google Earth Pro que se describen a continuación: 


\subsubsection{Fotografías Aéreas}

Las fotografías aéreas utilizadas fueron del Proyecto $\mathrm{N}^{\circ} 7986$ correspondiente a la zona de Toquepala - Quellaveco - Cuajone, con una escala promedio de 1:25 000, durante el mes de mayo del año de 1955, según índice grafico del Servicio Aerofotográfico Nacional (SAN) del Perú, como se observa en la figura 7.

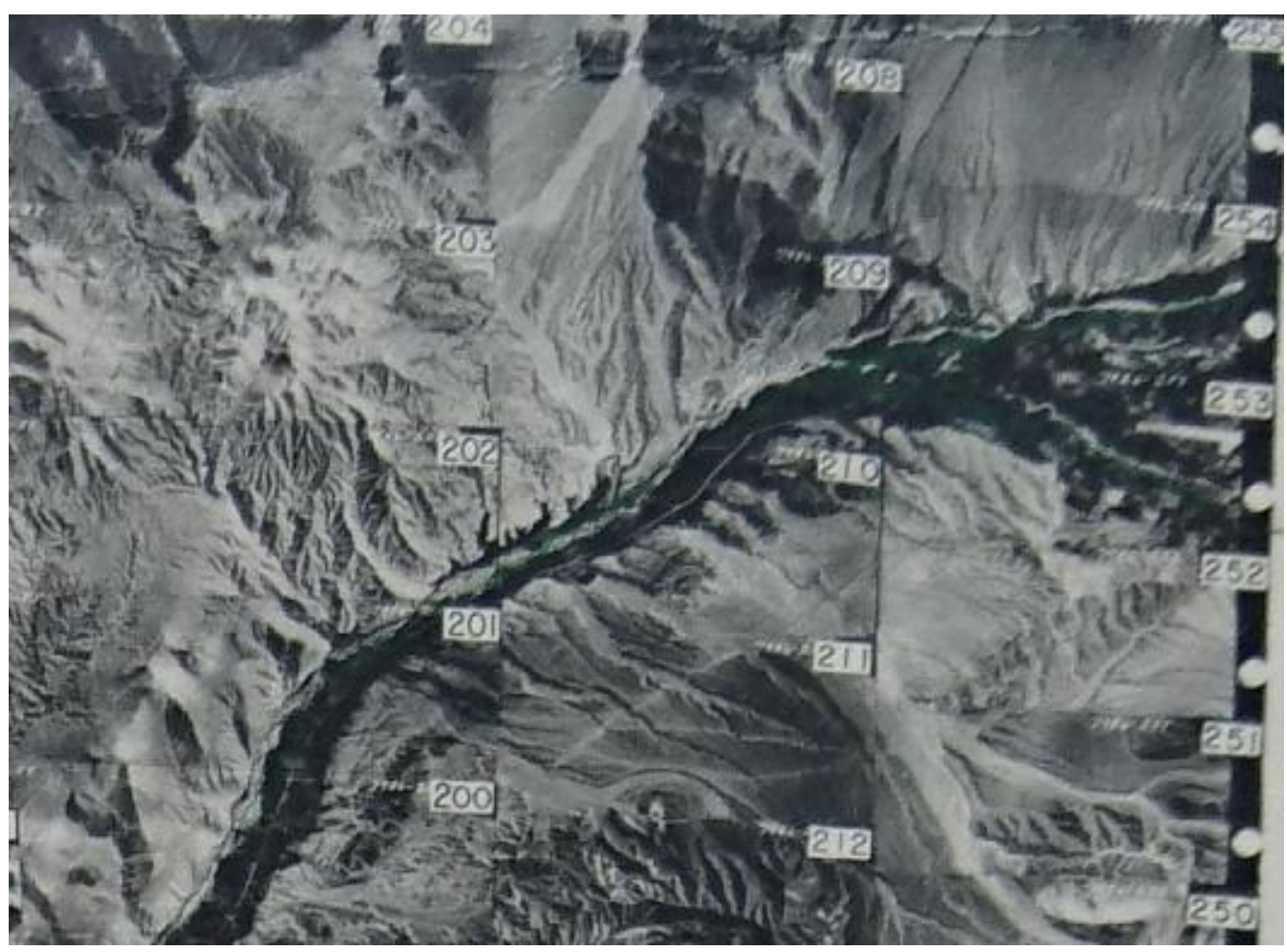

Figura 7. Mosaico de fotografías aéreas de la zona de estudio.

Fuente: Servicio Aerofotográfico Nacional del Perú.

\subsubsection{Imagen de Alta Resolución de Google Earth Pro}

La imagen de satélite de alta resolución fue descargada desde Google Earth Pro

7.3.2.5491, con fecha de compilación del 23 de julio del 2018, desde el servidor kh.google.com, como se observa el área de estudio en la figura 8. 


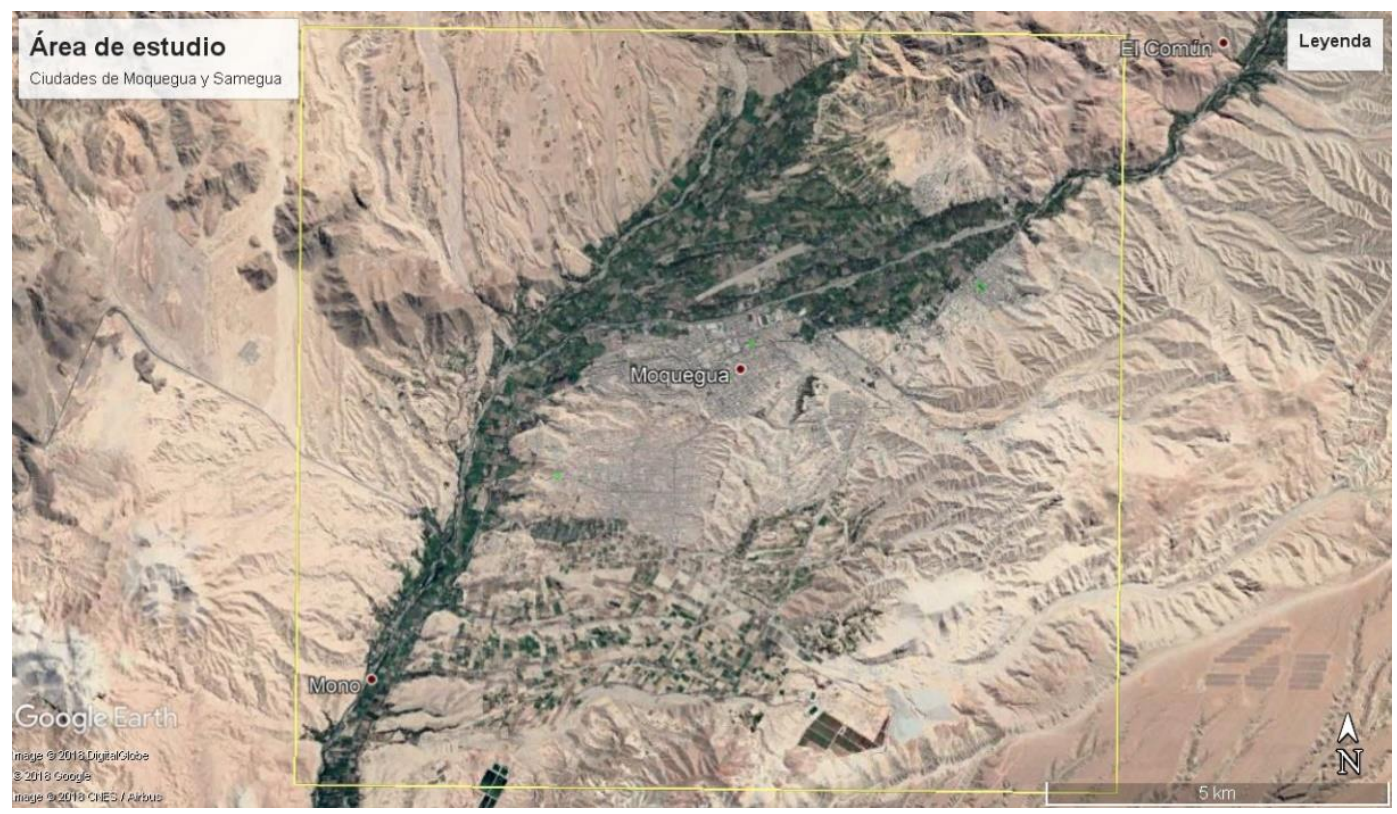

Figura 8. Imágenes de alta resolución de Google Earth Pro.

Fuente: Elaboración propia con imagen de Google Earth Pro.

\subsubsection{Métodos}

La metodología para clasificar el uso y cobertura de la tierra en nuestra área estudio es de acuerdo a la Clasificación Corine Land Cover mostrada en la tabla 1 (CORINE Land cover, 1994), metodología adoptada por el Ministerio del Ambiente de Perú (Arnillas et al., 2014), en nuestro trabajo utilizaremos la clasificación del Nivel I, pero modificada en la cuarta clase que corresponde a áreas húmedas por áreas de yacimiento arqueológico, debido a que en nuestra zona no existe áreas húmedas continentales, pero existe áreas de yacimientos arqueológicos de gran importancia en el Departamento, con lo que tendremos una clasificación Corine Land Cover modificada para el uso y cobertura de la tierra, colocando la denominación de las coberturas de acuerdo a la mayor área que se identifica en nuestra área de estudio como es la clase 3 que tenemos áreas sin o poca vegetación, que se observa en la tabla 2. 
Tabla 1

Categorías de la Clasificación Corine Land Cover

\begin{tabular}{lll}
\hline Nivel_I & Nivel_II & Nivel_III \\
\hline 1. Áreas & 1.1. Áreas urbanizadas & 1.1.1. Tejido urbano continuo \\
Artificializadas & 1.2. Áreas industriales e & 1.2.4. Aeropuerto \\
& 1.3. Áreas de extracción de & 1.3.1. Áreas de extracción de \\
\hline & 2.1. Cultivos transitorios &
\end{tabular}

2. Áreas

Agrícolas

2.2. Cultivos permanentes

2.4. Áreas agrícolas $\quad$ 2.4.1. Mosaico de cultivos

3.1.1. Bosque denso bajo

3.1. Bosques

3.1.2. Bosque abierto bajo

3.1.3. Bosque denso alto

3. Bosques y

3.1.4. Bosque abierto alto

3.2. Bosques plantados 3.2.1. Plantación Forestal

áreas

3.3. Áreas con vegetación 3.3.1. Herbazal

mayormente herbácea y/o arbustivo

3.3.4. Vegetación arbustiva /

naturales

3.4.1. Áreas arenosas naturales

3.4. Áreas sin o con poca $\quad 3.4 .2$. Afloramientos rocosos

3.4.3. Tierras desnudas (incluye

vegetación

3.4.4. Áreas quemadas

3.4.5. Glaciares

4. Áreas 4.1.1. Áreas Pantanosas

4. Áreas 4.1. Áreas húmedas 4.1.2. Turberas y bofedales

húmedas continentales 4.1.3. Vegetación acuática sobre

cuerpos de agua

5.1.1. Ríos $(50 \mathrm{~m})$

5. Superficies de

Agua

5.1.2. Lagunas, lagos y ciénagas

5.1. Aguas continentales 5.1.3. Lagunas, lagos y ciénagas

5.1.5. Cuerpos de agua

artificiales

Fuente: (CORINE Land cover, 1994) 


\section{Tabla 2}

Categorías de la Clasificación Corine Land Cover modificada para el análisis de uso y cobertura de la tierra entre los años de 1955 y 2018 de área de estudio.

\section{Categorías de uso y cobertura de la tierra}

1. Superfície Artificial

2. Zona Agrícola

3. Sin/Poca Vegetación

4. Yacimiento Arqueológico

5. Cuerpo Agua

2.2.3.1. Para identificar y cartografiar las categorías y distribución espacial del uso y cobertura de la tierra de 1955 a partir de Fotografías Aéreas.

El procedimiento metodológico para crear la cartografía de las categorías y distribución espacial del uso y cobertura de la tierra de 1955 se ejecutó en las siguientes etapas:

\section{Primera Etapa: Trabajos de georreferenciación y georrectificación.}

Las aerofotografías del año 1955 no están georreferenciadas, es decir, no se les ha atribuido información espacial o no poseen ningún sistema de proyección cartográfica, ni están posicionadas en el espacio correctamente. Las aerofotografías presentan una distorsión de escala, la misma que resulta nula en el área central de la imagen y va aumentando progresivamente hacia los márgenes de la fotografía. Estos procesos de georrectificación y georreferenciación resultan ser técnicas laboriosas por ser lentos y detallados para lograr una representación vectorial del área de estudio, se realizan los siguientes procedimientos: 


\section{a) Escaneo de las fotografías aéreas}

El escaneo de la fotografía aérea debe tener una resolución mayor a 600 DPI (Dots Per Inch) o puntos por pulgada (ppp) para obtener una óptima definición de la aerofotografía, que nos permite obtener información clara y real. Para el almacenamiento de la información digital escaneada es recomendable que sea en formato de archivo de imágenes etiquetada TIFF porque no emplea algoritmos de compresión, especialmente para estos casos de fotografías aéreas ya que requerimos alta resolución y calidad de una representación más profesional.

\section{b) La georreferenciación de la aerofotografía}

En este estudio la georreferencia se realiza con la extensión Georreferencing de la aplicación ArcMap de ArcGIS, la misma que tiene varias herramientas que permiten desarrollar la georreferencia en la fotografía de modo que este ajustada lo más posible al espacio real de estudio considerando los siguientes pasos:

\section{Paso 1: Alinear la aerofotografía con puntos de control}

Para tal fin se de buscar punto comunes entre la aerofotografía y los puntos control o cartografía base, en nuestro estudio la cartografía base fueron las imágenes de World Imagery (WGS84), desde los servicios de mapas con almacenamiento de ArcGIS Online, que proporciona imágenes satelitales y aéreas de un metro o más en muchas partes del mundo (ESRI, 2018). Este procedimiento de dar puntos de referencia entre imagen y puntos de control de la cartografía base, se realiza con la herramienta Add Control Points. Como podemos observar en la figura 9 la georreferencia para la aerofotografía 710. 


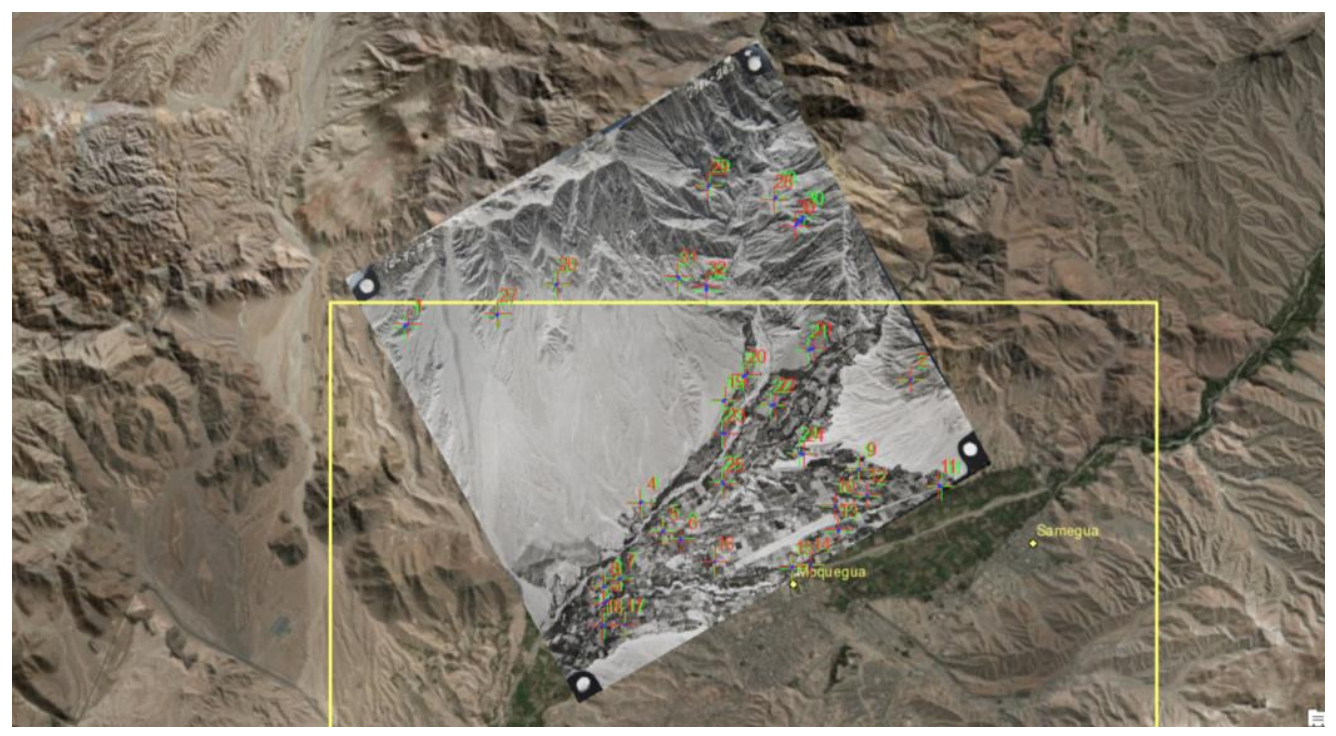

Figura 9. Alineación de la aerofotografía 710 con puntos de control.

Fuente: Elaboración propia con datos del SAN y del World Imagery (ESRI, 2018).

\section{Paso 2: Transformar la aerofotografía}

Después de crear suficientes vínculos, comenzamos a transformar la aerofotografía (dataset ráster) de forma permanente, para ello se tiene 7 métodos de transformación:

1) 1 st Order Polinomial (Affine)

2) 2st Order Polinomial

3) 3st Order Polinomial

4) Ajust

5) Projective Transformation

6) Spline

7) Zero Order Polinomial (Shift)

Podemos observar cada una de estas transformaciones, para ver los puntos usamos la herramienta View Link Table, para ver los puntos comunes entre los puntos de la aerofotografía y el mapa base en la tabla Link, mostramos como 
ejemplo los procesos realizados con la aerofotografía 710 en las figuras del 10 al

16:

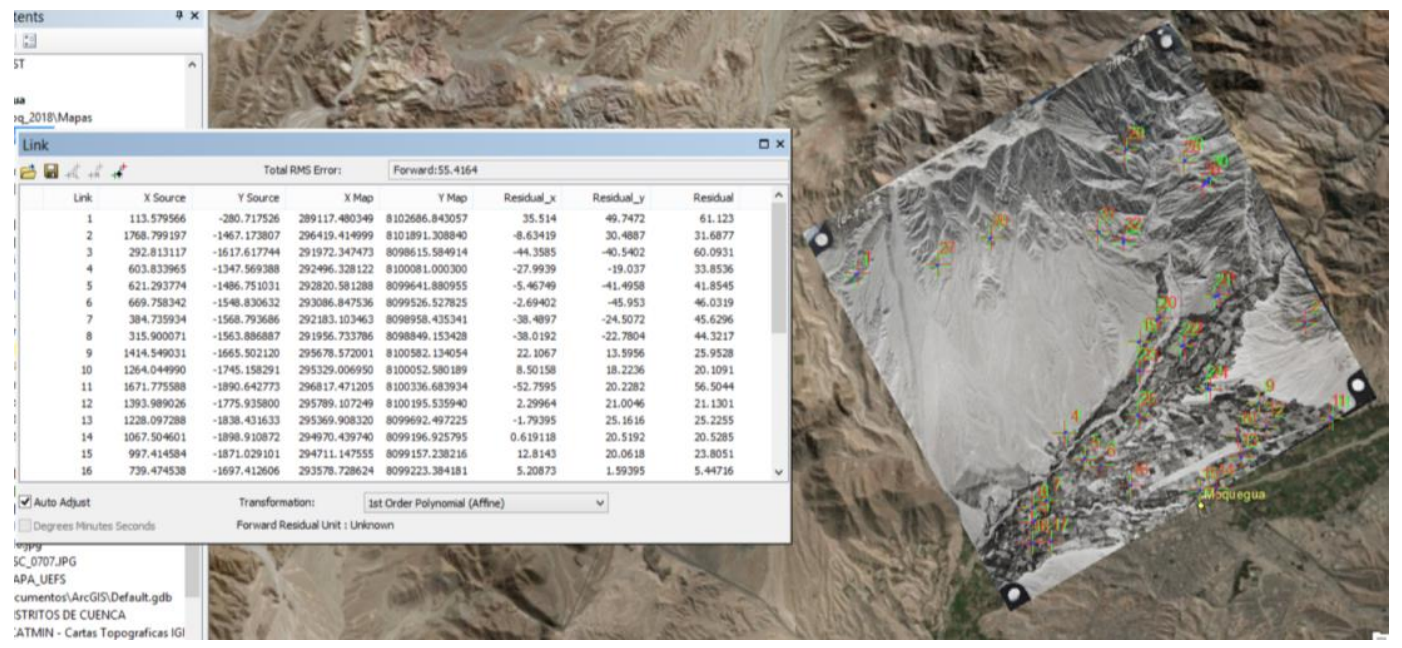

Figura 10. Transformación de la aerofotografía por el método 1st Order Polinomial (Affine).

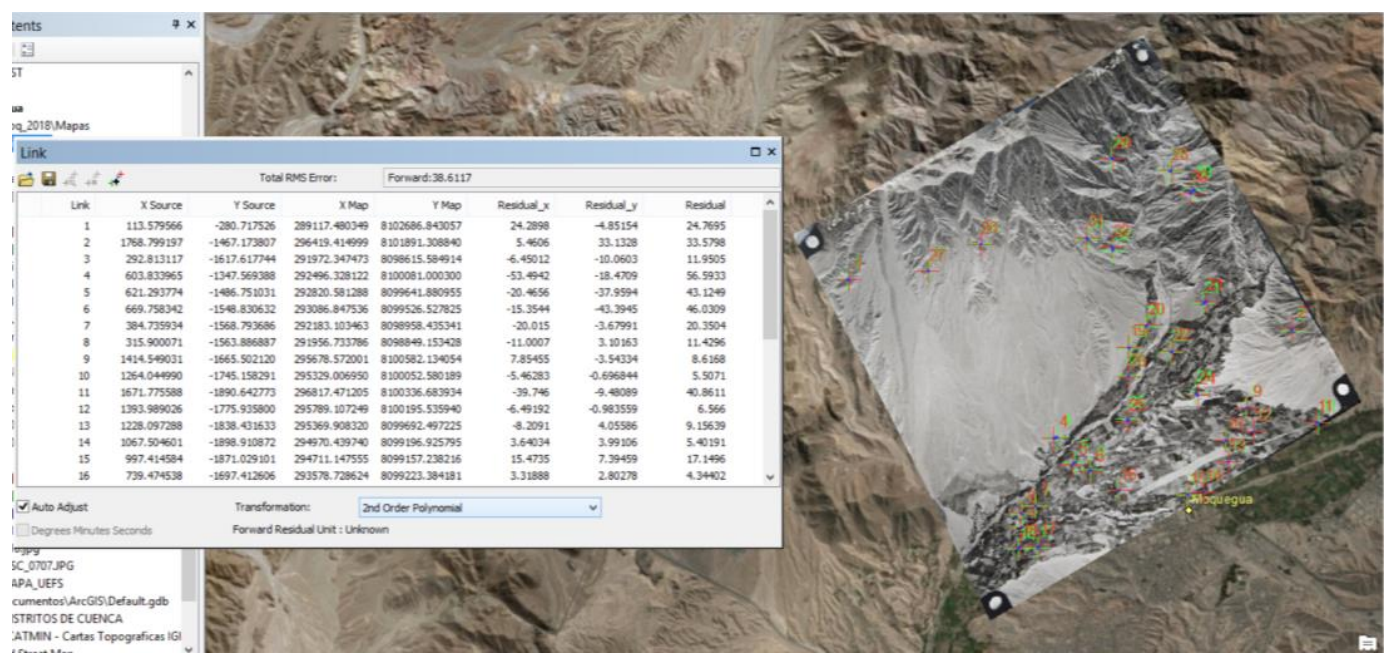

Figura 11. Transformación de la aerofotografía por el método 2st Order Polinomial. 


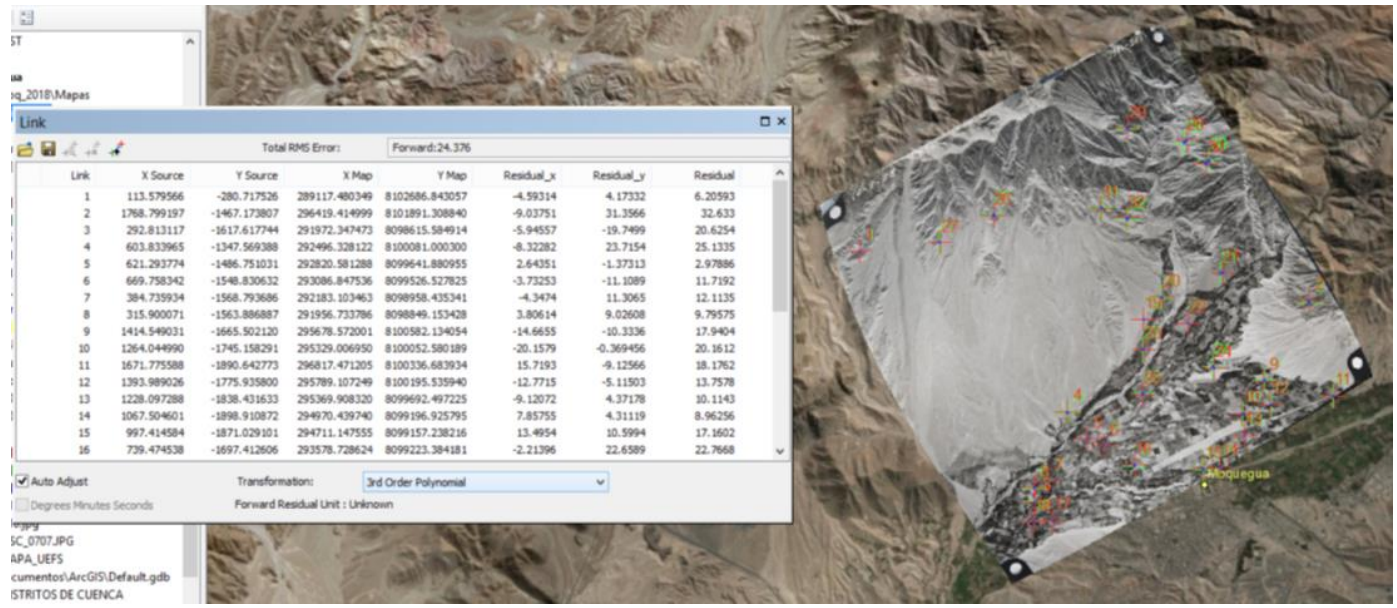

Figura 12. Transformación de la aerofotografía por el método 3st Order Polinomial.

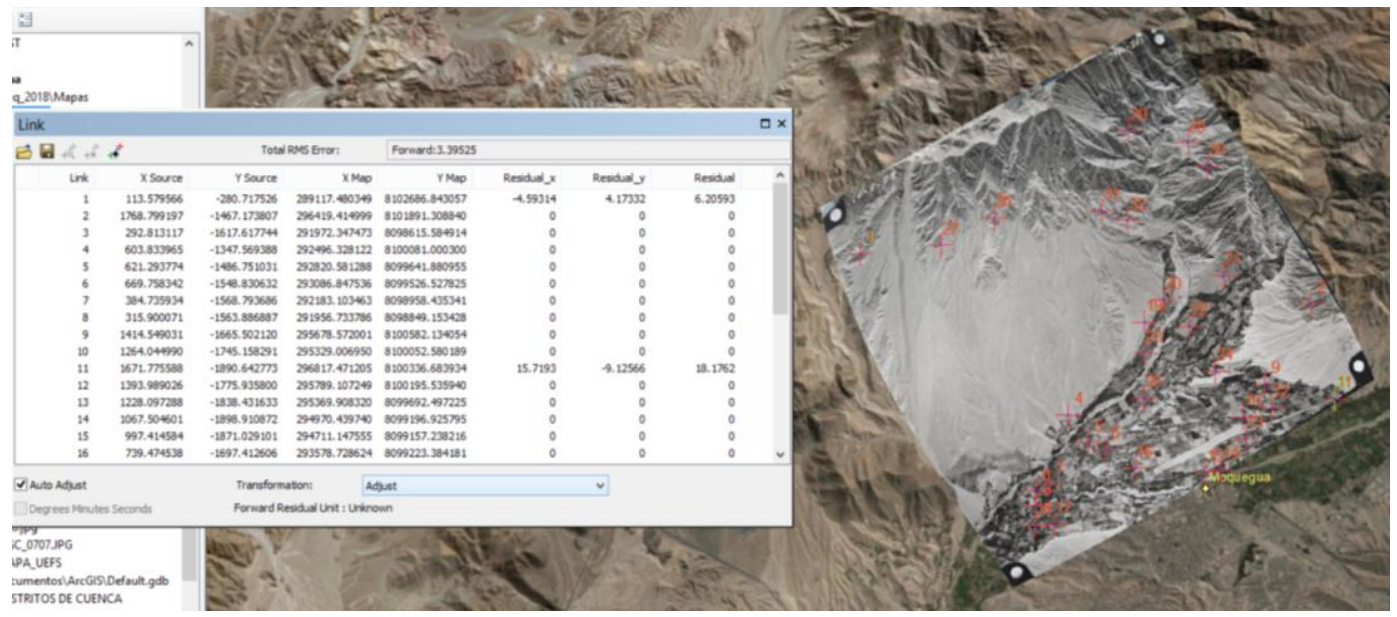

Figura 13. Transformación de la aerofotografía por el método Ajust.

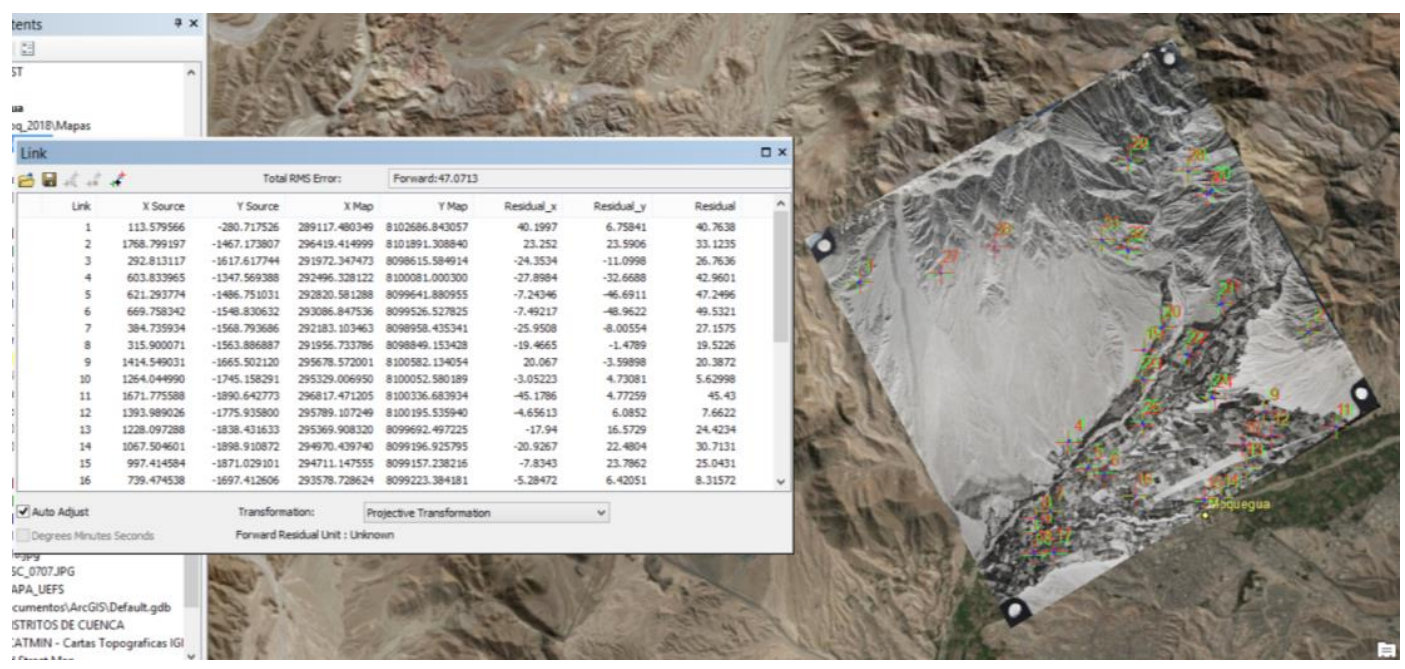

Figura 14. Transformación de la aerofotografía por el método Projective Transformation. 


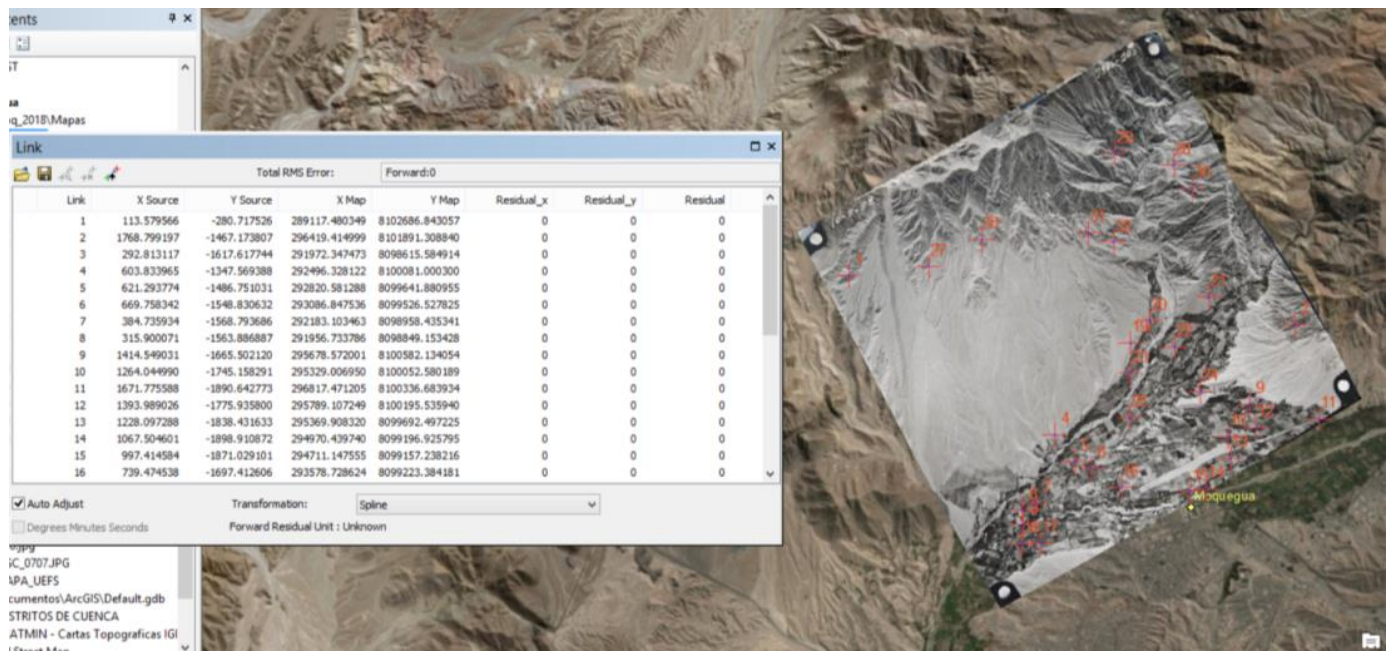

Figura 15. Transformación de la aerofotografía por el método Spline.

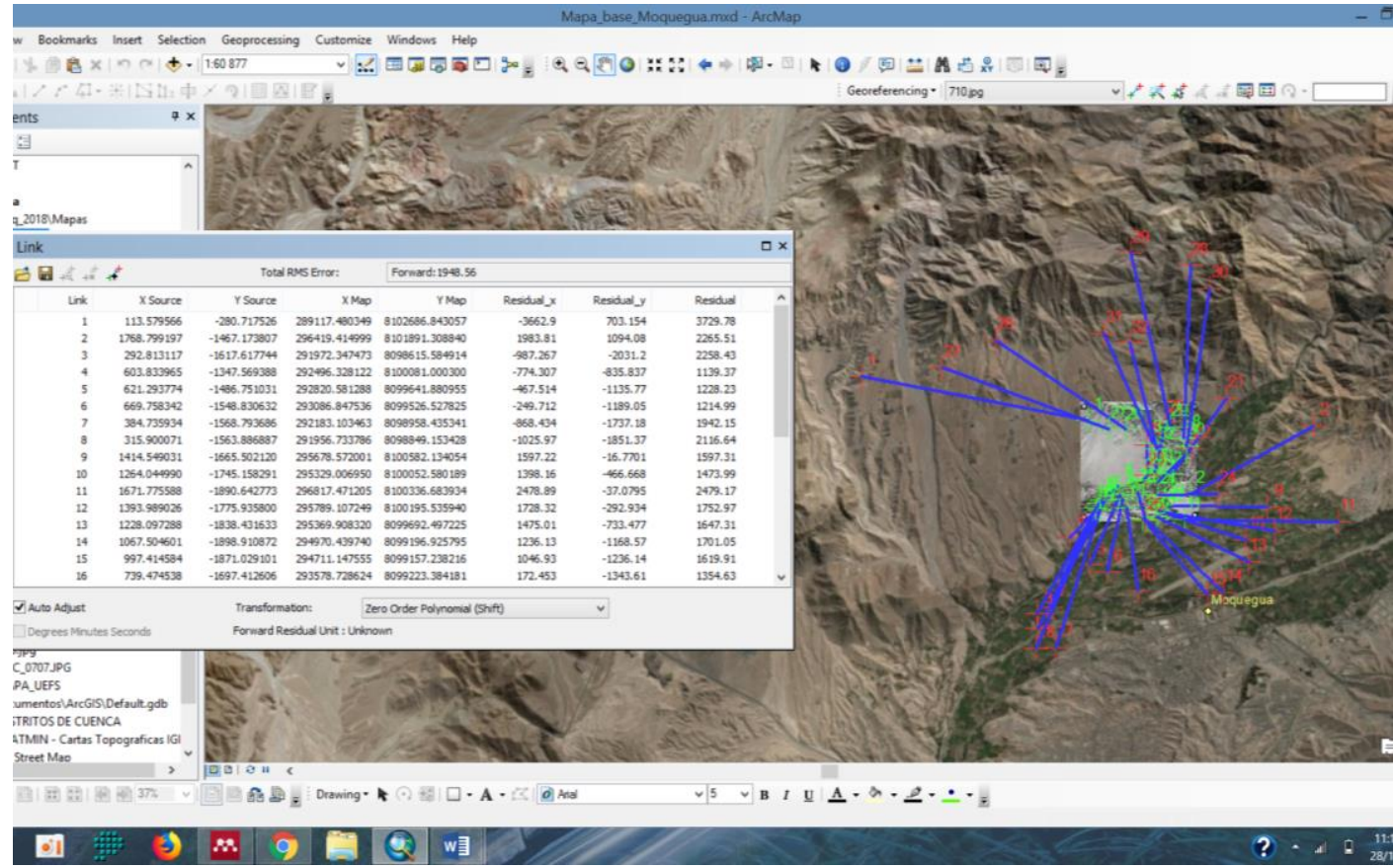

Figura 16. Transformación de la aerofotografía por el método Zero Order Polinomial (Shift).

En nuestro estudio utilizamos la transformación por el método spline, considerando que es una metodología efectiva de deformación elástica vectorial y optimiza para la exactitud local, pero no para la global. Se fundamenta en la función por spline, es una función polinómica por partes que conserva la continuidad y suavidad entre polinomios adyacentes. 


\section{Paso 3: Interpretar el error cuadrático medio.}

Como se observa en las figuras $10,11,12,13,14,15$ y 16 son las transformaciones de la aerofotografía 710 con la tabla Link correspondiente para cada uno de los métodos, en ella se muestra el error (error residual) en cada punto, es decir, la diferencia entre dónde acabó el punto de partida, frente a la ubicación real especificada (la posición del punto de destino). El error total es calculado por la suma cuadrática media RMS (Root Mean Squar) mostrado en la pestaña Total RMS Error, cuyo valor describe el grado de coherencia de la transformación. Cabe indicar que cuantos más puntos de control se realicen, más preciso será el polinomio al momento de transformar los datos de entrada en coordenadas de salida. Se recomienda que cuando los errores son fundamentalmente grandes, se pueden quitar y agregar nuevos puntos de control para su ajuste.

\section{c) La georrectificación de la aerofotografía}

Para georrectificar o rectificar o transformar, proyectar o remuestrear la aerofotografía se realiza con el comando Rectify para convertir de una proyección a otra; como para hacer cambios en el tamaño de celda, en nuestro caso utilizamos el método nearest neighbor (vecino más cercano) y quedando almacenado en un archivo con la extensión TIFF. Seguidamente utilizamos el comando Update Georeferencing para almacenar la información de transformación en los archivos.

Segunda Etapa: Procesos de fotointerpretación y cartografiado de la aerofotografía.

Se realizan los siguientes procedimientos: 


\section{a) Fotointerpretación de la fotografía aérea}

La interpretación de la fotografía aérea permite discernir y delinear las cinco categorías establecidas de uso y cobertura de la tierra de 1955, con base en las siguientes características:

- $\quad$ Tipo de límites entre categorías

- Presencia de lineamientos en el uso y cobertura a clasificar

- Tipo y claridad de los límites del uso y cobertura a clasificar

- Tamaño de la unidad del uso y cobertura a clasificar

- Forma y delineamiento del uso y cobertura a clasificar

- Homogeneidad en el uso y cobertura a clasificar

- Tono y textura.

\section{b) Cartografiado de la fotografía aérea}

Para cartografiar la fotografía aérea utilizamos las aplicaciones ArcMap, ArcCatalog y ArcToolbox de ArcGIS, creando niveles de información específicos y almacenar los polígonos (shapefile: almacena ubicación geométrica e información de atributo de cada entidad geográfica) resultantes de las delimitaciones comunes para una determinada clase de uso y cobertura de la tierra; como observamos en la figura 17, el polígono amarillo corresponde a la Superficie Artificial en la que se encentra la ciudad de Moquegua en Mayo de 1955, el polígono verde que corresponde la Zona Agrícola, se realizado por el método de vectorización manual de la fotografía 707. 


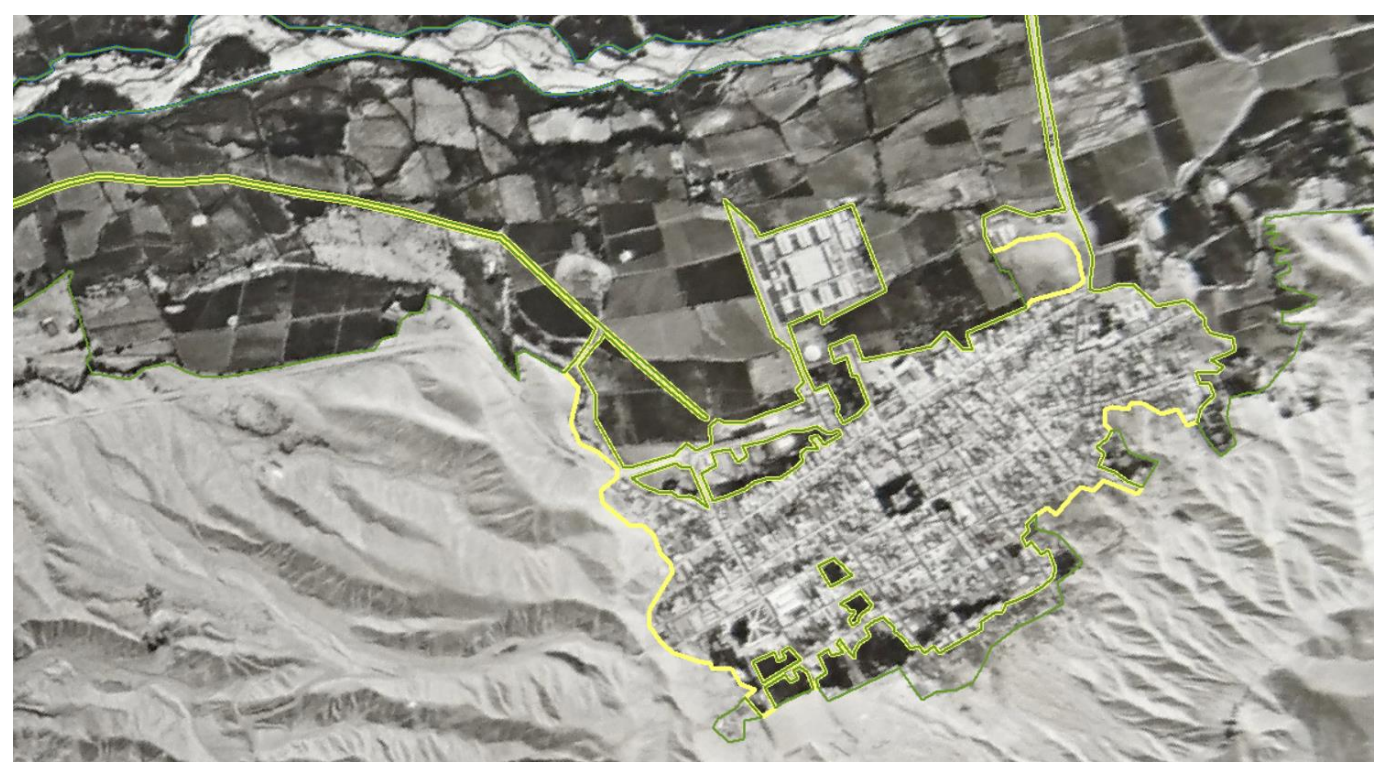

Figura 17. Vectorizado manual de la ciudad de Moquegua en 1955.

De esta manera se logra vectorizar toda el área de estudio, como se observa en la figura 18, los polígonos del uso y cobertura de la tierras de la ciudad de Moquegua y el pueblo de Samegua correspondientes a Superficie Artificial, Cuerpo de Agua, Yacimiento Arqueológico, Zona Agrícola y Sin/Poca Vegetación y el mosaico de las aerofotografías 706, 707, 709, 710 y 713 correspondientes a esta cobertura.

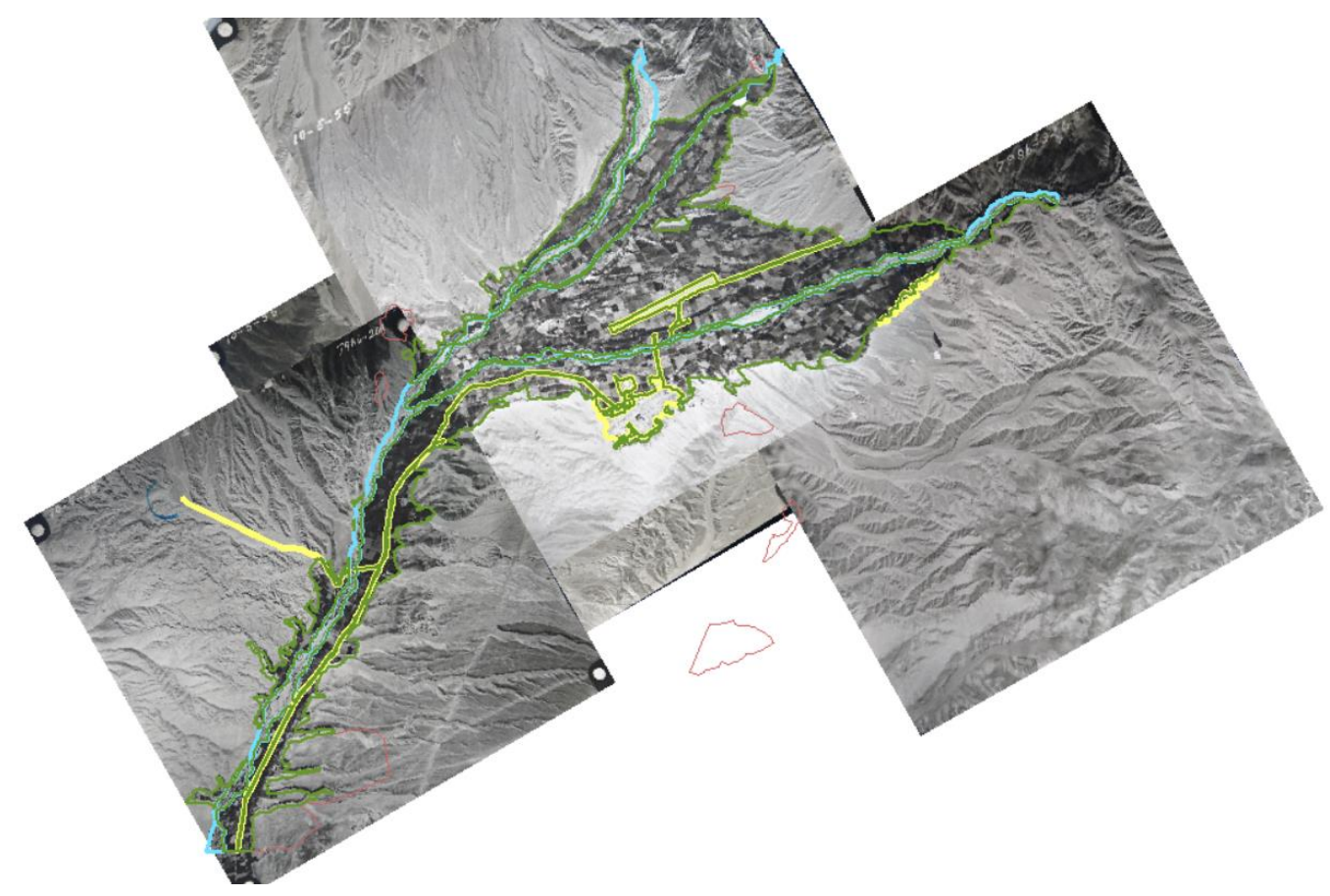

Figura 18. Vectorizado de la cobertura vegetal del área de estudio. 
En la sección 2.3.1. Presentación de resultados se presenta la figura 19 donde se muestra la cartografía de los usos y cobertura de la tierra de la ciudad de Moquegua y el pueblo de Samegua para el 1955.

Tercera Etapa: Construcción de la base de datos en el sistema de información geográfica.

Una vez construida la cartografía para 1955 podemos implementar la base de datos con las herramientas de ArcMap, como el cálculo de área por cobertura y el porcentaje como se muestra en la figura 19.

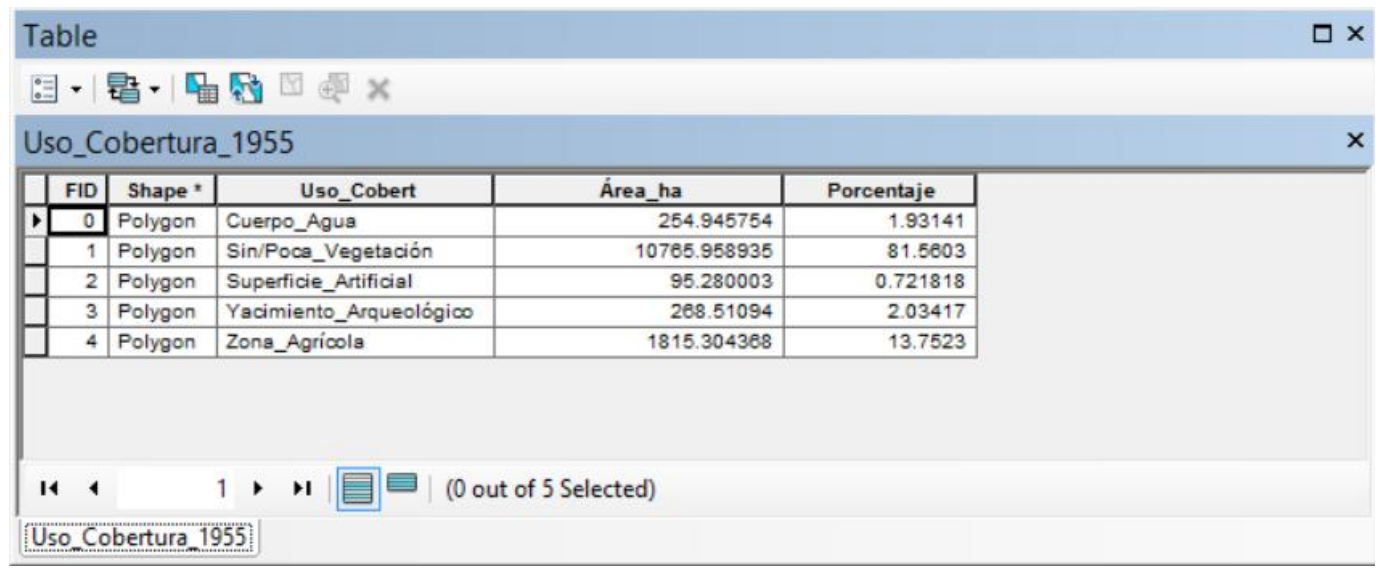

Figura 19. Construcción de base de datos para el uso y cobertura de la tierra de la ciudad de Moquegua y el pueblo de Samegua de 1955.

\subsubsection{Para identificar y cartografiar las categorías y distribución espacial del} uso y cobertura de la tierra de 2018 a partir de imágenes de Google Earth.

El procedimiento metodológico es similar que se utilizó para las aerofotografías solo que aquí se utiliza una sola imagen para toda el área de estudio, con la que se creó la cartografía de las categorías y distribución espacial del uso y cobertura de la tierra de 2018, se realizaron las siguientes etapas: 


\section{Primera Etapa: Trabajos de georreferenciación y georrectificación.}

Se requiere realizar los siguientes procesos:

\section{a) Obtención de imagen de alta resolución de Google Earth}

La captura de la imagen de Google Earth mostrada en la figura 8, es descargada desde el software SAS,Planet ver figura 20.

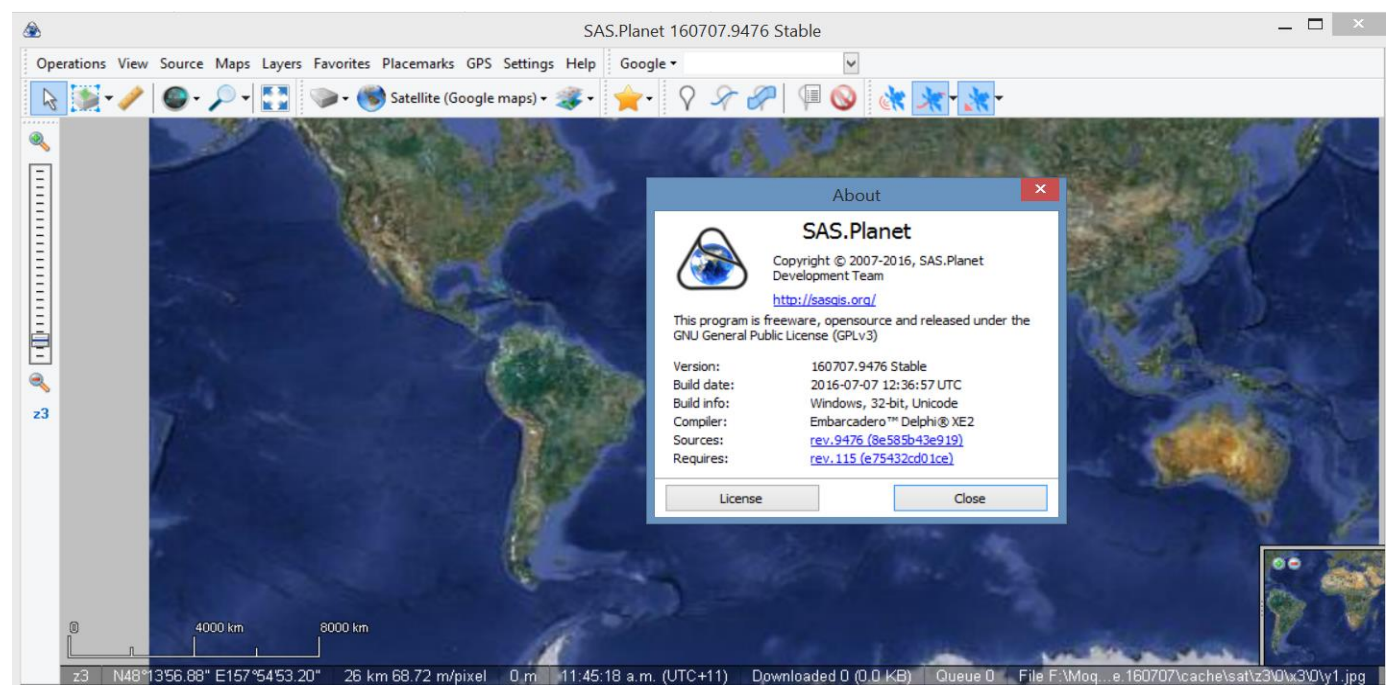

Figura 20. Software SAS,Planet para descargar imágenes desde Google Earth.

Pero la descarga tiene muchas imágenes pequeñas, luego tenemos que unir todas ellas con el software Global Mapper 20, mostrado en la figura 21.

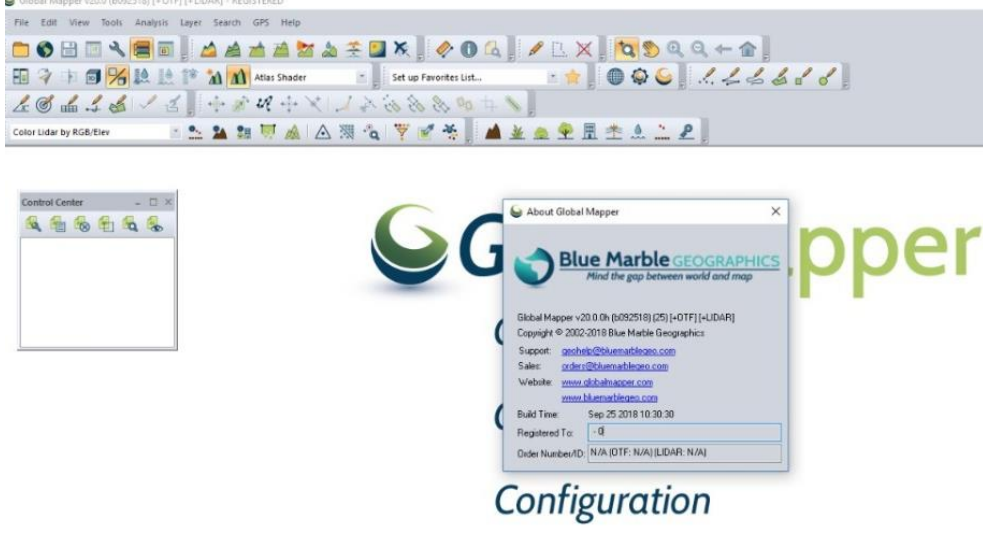

Load Default Data

Figura 21. Software global Mapper para unir todas las imágenes de SAS.Planet. 


\section{b) La georreferenciación de la imagen satelital}

Se realizan los mismos procedimientos igual que las fotografías aéreas.

Segunda Etapa: Procesos de fotointerpretación y cartografiado de la imagen satelital de alta resolución.

Se realizan los mismos procedimientos que en la fotografía aérea. Como podemos observar en la figura 22, el polígono amarillo corresponde a la Superficie Artificial en la que se encuentran la ciudad de Moquegua y el pueblo de Samegua unidas en el 2018, el polígono verde que corresponde la Zona Agrícola, se realizado por el método de vectorización manual de la imagen satelital.

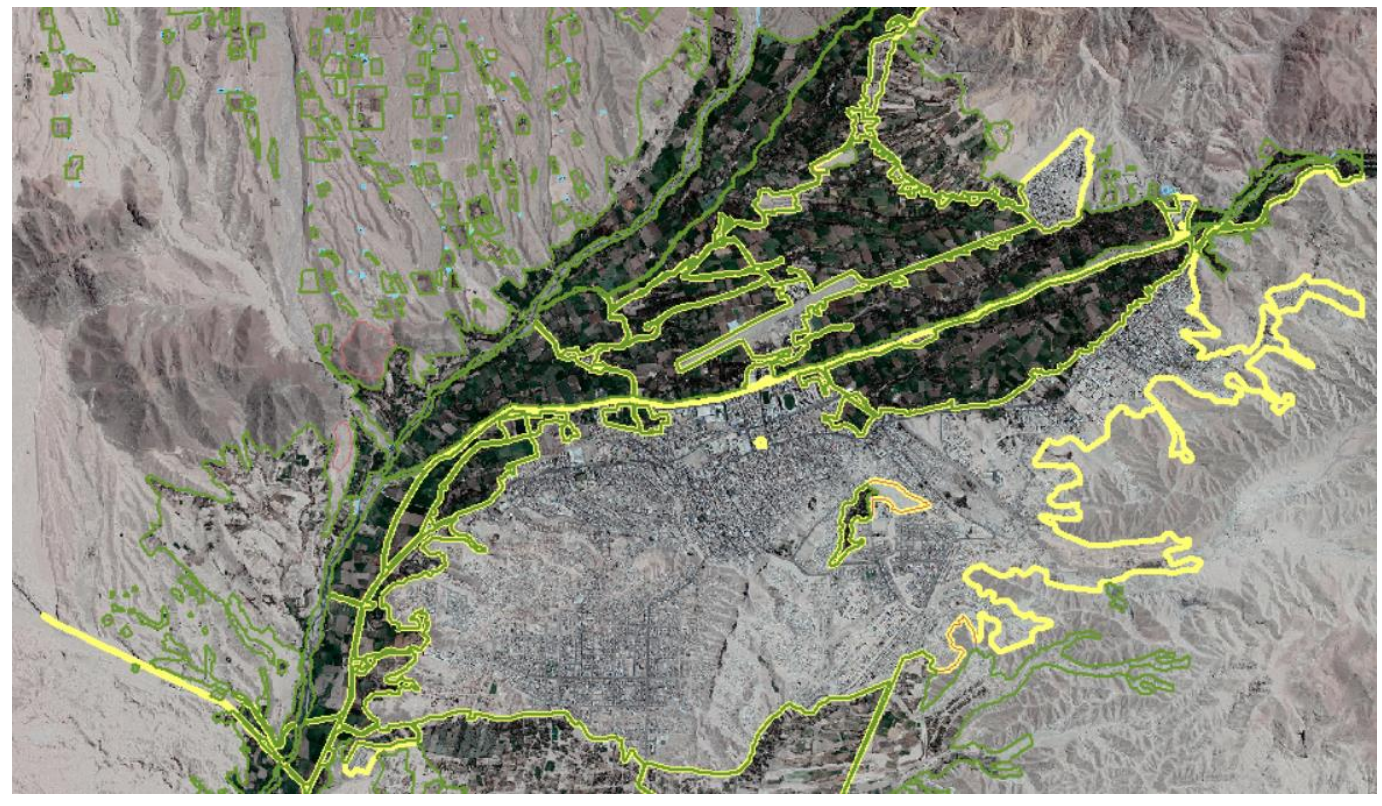

Figura 22. Vectorizado manual de la ciudad de Moquegua y el pueblo de Samegua en 2018.

En la sección 2.3.1. Presentación de resultados se presenta los mapas de uso y cobertura de la tierra de la ciudad de Moquegua y el pueblo de Samegua para el 2018 
Tercera Etapa: Construcción de la base de datos en el sistema de información geográfica.

Una vez construida la cartografía del 2018 podemos implementar la base de datos con las herramientas de ArcMap, como el cálculo de área por cobertura y el porcentaje como se muestra en la figura 23.

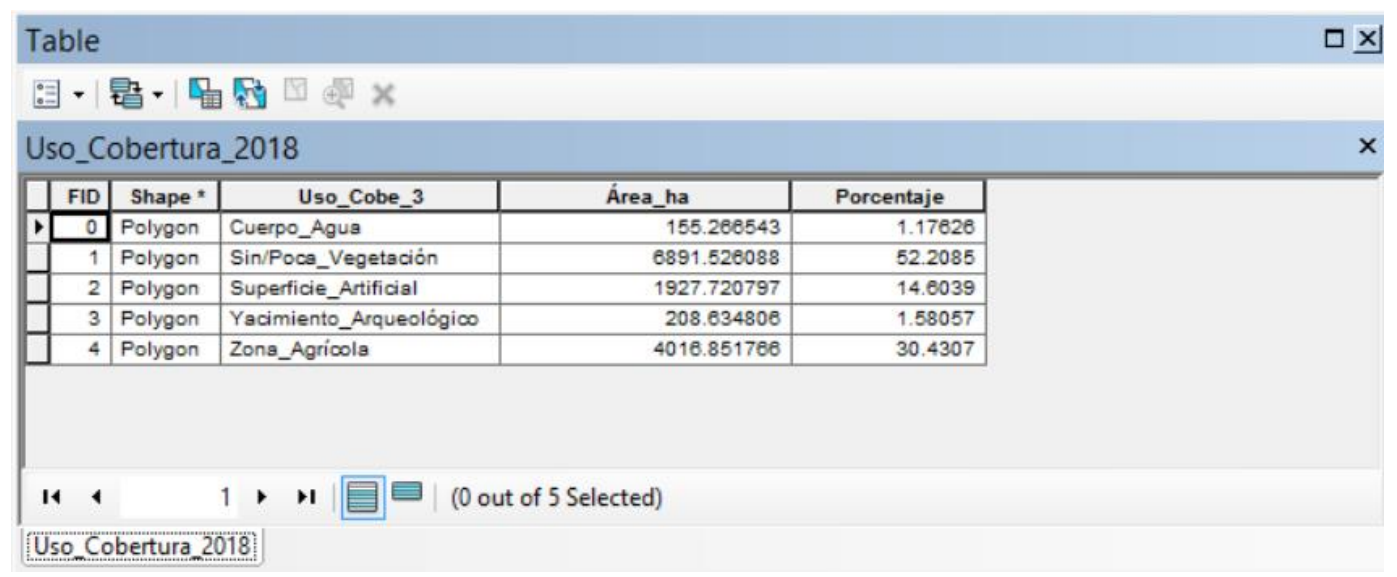

Figura 23. Construcción de base de datos para el uso y cobertura de la tierra de la ciudad de Moquegua y el pueblo de Samegua del 2018.

\subsubsection{Para identificar, cartografiar y analizar las áreas de cambio de uso y} cobertura de la tierra en la ciudad de Moquegua y el pueblo de Samegua entre 1955 y 2018.

Para la identificación, cartografiado y sobre todo el análisis de las áreas de cambio del uso y cobertura de la tierra en la ciudad de Moquegua y el pueblo de Samegua entre 1955 y 2018, se utiliza la matriz de tabulación cruzada propuesto por Pontius, Shusas, \& Mceachern (2004), esta matriz también es conocida también como matriz de transición (Schweitzer \& Farinelli, 2014), siendo una metodología principal para iniciar el análisis de los cambios de uso y cobertura de la tierra, para obtener la mayor información posible sobre los procesos potenciales que determinan un patrón 
de cambio de la tierra. Con la metodología de la matriz de tabulación cruzada evaluaremos el cambio total de las categorías de uso y cobertura de la tierra según dos pares de componentes, que en nuestro estudio de caso son los mapas 1955 y 2018

La matriz de la tabla 3 es la que propuso Pontius, Shusas, \& Mceachern (2004) y el proceso a seguir será el mismo, donde cada fila representa la categoría del mapa en el tiempo $1\left(T_{1}\right)$ y cada columna la categoría del mapa en el tiempo 2 $\left(T_{2}\right)$. También, se observa que la diagonal principal representan los espacios que permanecen entre el $T_{1}$ y $T_{2}$, y los demás valores que no se encuentran en la diagonal principal representan las transiciones acontecidas durante el $T_{1}$ y $T_{2}$ por cada una de las categorías. En la fila Total Tiempo 2 se suma el total ocupado en cada una de las categorías en el $T_{2}\left(P_{+n}\right)$, similar a ello en la columna Total Tiempo 2 se suma el total ocupado en cada una de las categorías en el $T_{1}\left(P_{n+}\right)$. En la última fila se muestra los valores de la ganancia que tuvieron cada una de las categorías entre $T_{1}$ y $T_{2}$ y la última columna muestra los valores de la pérdida que tuvieron cada una de las categorías entre $T_{1}$ y $T_{2}$.

Tabla 3

Matriz de tabulación cruzada general para comparar dos mapas de diferentes puntos en el tiempo

\begin{tabular}{ccccccc}
\hline & Tiempo 2 & \multicolumn{3}{c}{ Total Tiempo 1 } & Pérdida \\
\cline { 2 - 5 } & Categoría & Categoría & Categoría & Categoría & & \\
\hline Tiempo 1 & 1 & 2 & 3 & 4 & $P_{1+}$ & $P_{1+}-P_{11}$ \\
Categoría 1 & $P_{11}$ & $P_{12}$ & $P_{13}$ & $P_{14}$ & $P_{2+}$ & $P_{2+}-P_{22}$ \\
Categoría 2 & $P_{21}$ & $P_{22}$ & $P_{23}$ & $P_{24}$ & $P_{3+}$ & $P_{3+}-P_{33}$ \\
Categoría 3 & $P_{31}$ & $P_{32}$ & $P_{33}$ & $P_{34}$ & $P_{4+}$ & $P_{4+}-P_{44}$ \\
Categoría 4 & $P_{41}$ & $P_{42}$ & $P_{43}$ & $P_{44}$ & 1 & \\
Total Tiempo 2 & $P_{+1}$ & $P_{+2}$ & $P_{+3}$ & $P_{+4}$ & & \\
Ganancia & $P_{+1}-P_{11}$ & $P_{+2}-P_{22}$ & $P_{+3}-P_{33}$ & $P_{+4}-P_{44}$ & & \\
\hline
\end{tabular}

Fuente: (Pontius, Shusas, \& Mceachern, 2004) 


\subsection{Presentación y discusión de resultados}

\subsubsection{Presentación de resultados.}

Los resultados mostramos en el orden de los objetivos planteados, el primero corresponde al objetivo general y los tres siguientes a los objetivos específicos, que se indican a continuación:

1. Se logró analizar en espacio y tiempo los cambios de uso y cobertura de la tierra en la ciudad de Moquegua y el pueblo de Samegua entre 1955 y 2018 aplicando técnicas de geoprocesamiento, como resultado de ello se muestra el mapa de cambios totales en la figura 24 , donde se observa las zonas que cambiaron y las que no cambiaron.

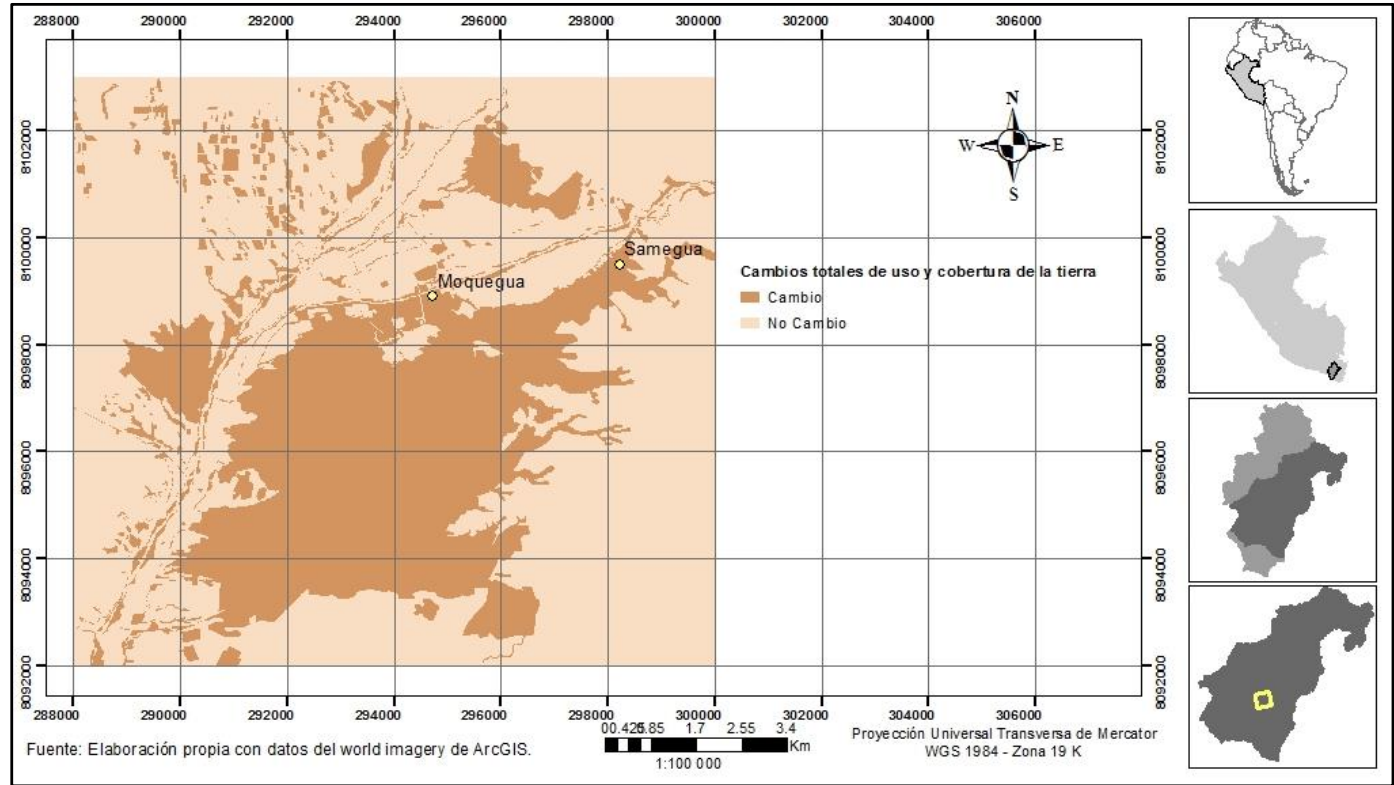

Figura 24. Cambios totales de uso y cobertura de la tierra de la ciudad de Moquegua y el pueblo de Samegua entre 1955 y 2018. 
2. Se logró identificar y cartografiar las categorías y distribución espacial del uso y cobertura de la tierra en la ciudad de Moquegua y el pueblo de Samegua de 1955 a partir de fotografías aéreas, cuyo resultado se presenta en la figura 25.

3. Se logró identificar y cartografiar las categorías categorías y distribución espacial del uso y cobertura de la tierra en la ciudad de Moquegua y el pueblo de Samegua del 2018 a partir de imágenes satelitales, como se presenta en la figura 26.

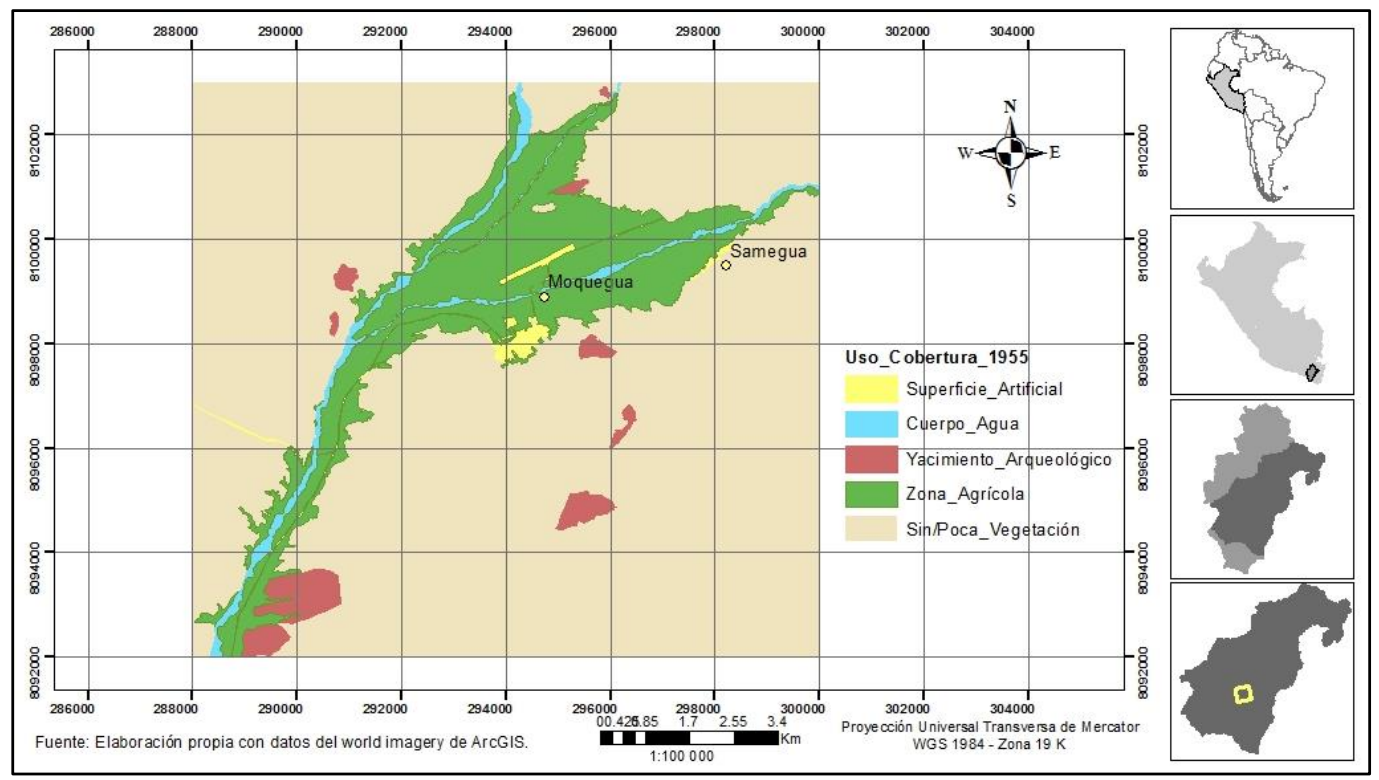

Figura 25. Mapa de uso y cobertura de la tierra de la ciudad de Moquegua y el pueblo de Samegua del año 1955. 


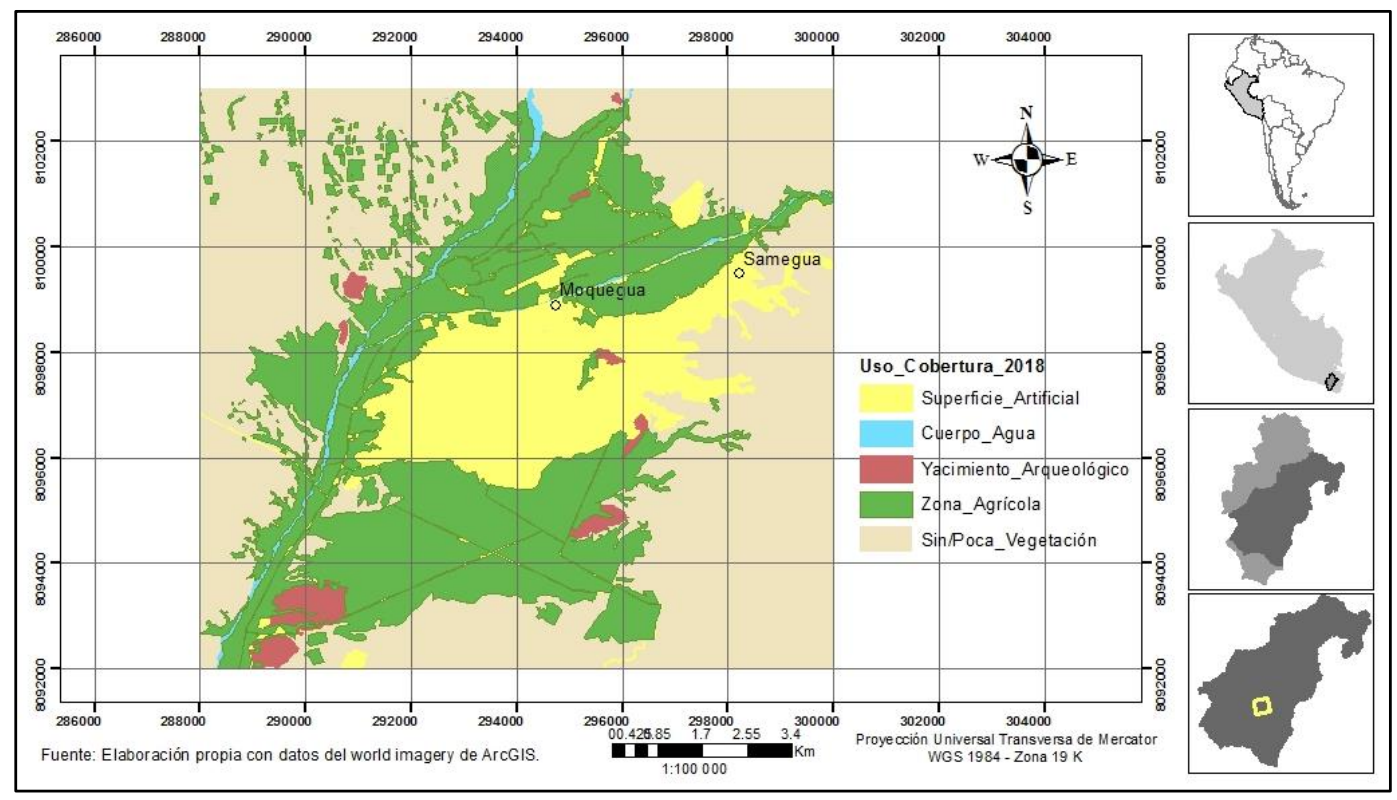

Figura 26. Mapa de uso y cobertura de la tierra de la ciudad de Moquegua y el pueblo de Samegua del año 2018.

4. Se logro identificar, cartografiar y analizar las áreas de cambio de uso y cobertura de la tierra en la ciudad de Moquegua y el pueblo de Samegua entre 1955 y 2018 con técnicas de geoprocesamiento, como podemos observar la figura 27. 


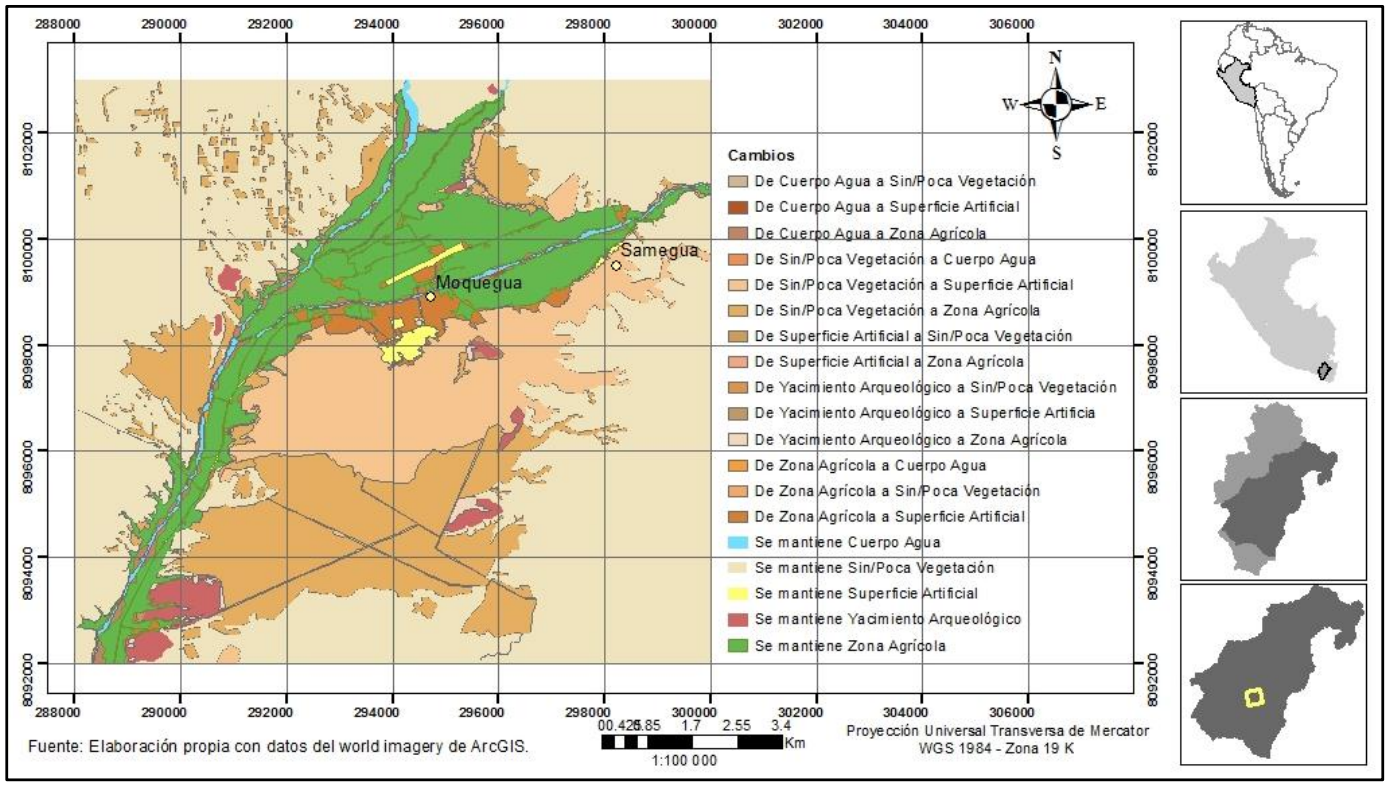

Figura 27. Mapa de cambios de uso y cobertura de la tierra de la ciudad de Moquegua y el pueblo de Samegua entre 1955 y 2018.

\subsubsection{Discusión de resultados.}

1. Observando el mapa de cambios totales de uso y cobertura de la tierra de la ciudad de Moquegua y el pueblo de Samegua entre 1955 y 2018 en la figura 24, podemos indicar que la ocupación de la superficie que "No cambio" es mayor que la superficie que "Cambio", ello se confirma con la tabla 4 y generada a partir de la figura 28, donde el área de "No Cambio" tiene 8 859,8 hectáreas y el área "Cambio" 4 340,2 hectáreas que expresados en porcentaje representan el $67 \%$ y $33 \%$ mostrados en la figura 28.

\section{Tabla 4}

Cambios totales de uso y cobertura de la tierra de la ciudad de Moquegua y el pueblo de Samegua entre 1955 y 2018.

\begin{tabular}{crc}
\hline Cambios totales de uso y cobertura de la tierra & Área (ha) & Porcentaje (\%) \\
\hline Cambio & 4340,20 & 33 \\
No Cambio & 8859,80 & 67 \\
Total & 13200,00 & 100 \\
\hline
\end{tabular}




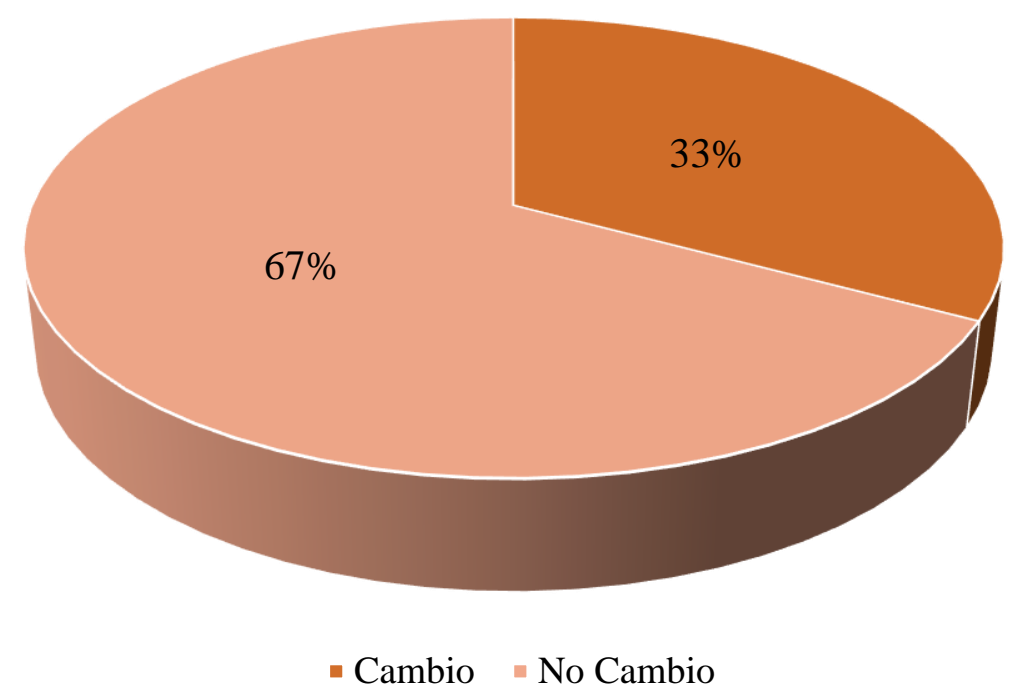

Figura 28. Porcentaje de Cambios totales de uso y cobertura de la tierra de la ciudad de Moquegua y el pueblo de Samegua entre 1955 y 2018.

2. El Mapa de uso y cobertura de la tierra de la ciudad de Moquegua y el pueblo de Samegua del año 1955 en la figura 25, nos muestra las 5 categorías de uso y cobertura de la tierra: "Superficie Artificial", "Cuerpo Agua", "Yacimiento Arqueológico", “Zona Agrícola” y “Sin/Poca Vegetación”; en el cual observamos que la cobertura "Sin/Poca Vegetación" ocupa mayor superficie en la zona de estudio y la cobertura "Superficie Artificial" ocupa menor superficie en la zona de estudio, confirmándonos con los cálculos de área en la tabla 5, donde identificamos que la cobertura "Sin/Poca Vegetación" tiene 10 765,96 hectáreas y la cobertura “Superficie Artificial” tiene 95,28 hectáreas que representan el $81,56 \%$ y $0,72 \%$ mostrados en la figura 29. 


\section{Tabla 5}

Categorías de uso y cobertura de la tierra de la ciudad de Moquegua y el pueblo de Samegua de 1955

\begin{tabular}{lrr}
\hline $\begin{array}{l}\text { Categorías de uso y cobertura de la tierra de } \\
\mathbf{1 9 5 5}\end{array}$ & \multicolumn{2}{c}{ Porcentaje } \\
\hline Superficie Artificial & 95,28 & 0,72 \\
Cuerpo Agua & 254,95 & 1,93 \\
Yacimiento Arqueológico & 268,51 & 2,03 \\
Zona Agrícola & 1815,30 & 13,75 \\
Sin/Poca Vegetación & 10765,96 & 81,56 \\
Total & $\mathbf{1 3 2 0 0 , 0 0}$ & $\mathbf{1 0 0 , 0 0}$ \\
\hline
\end{tabular}

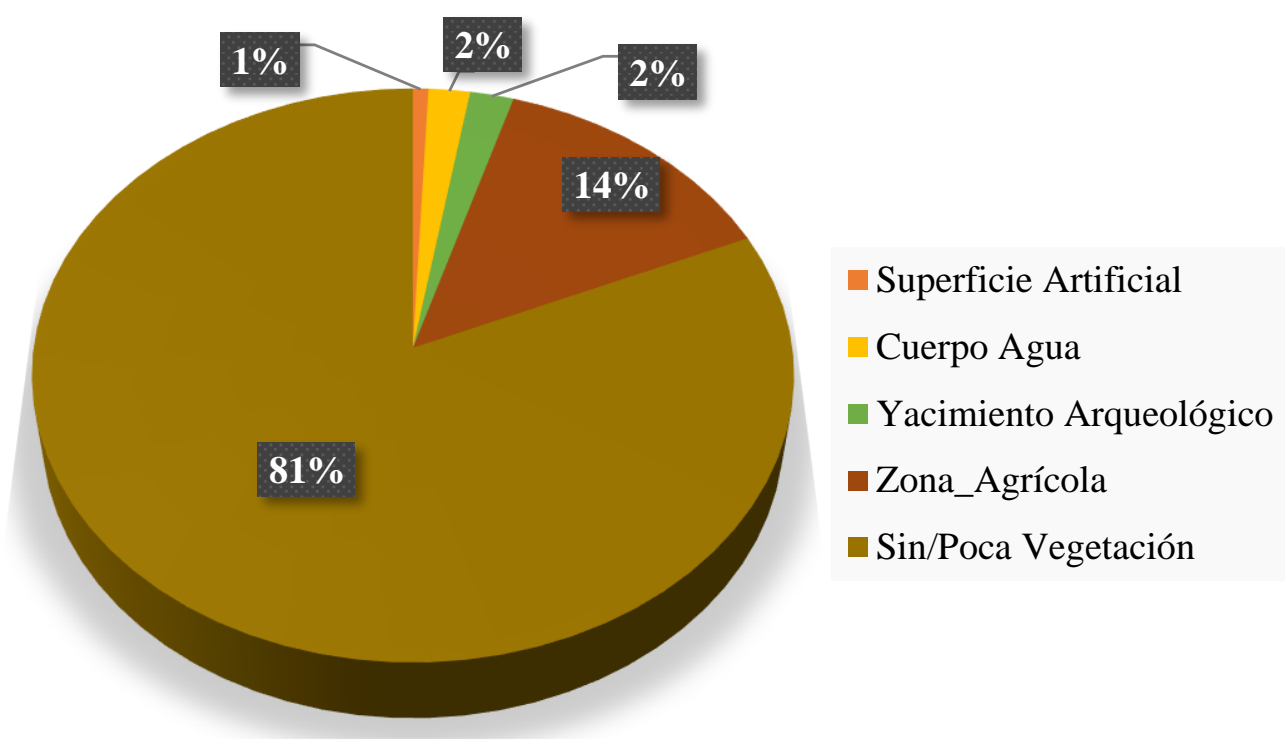

Figura 29. Categorías de uso y cobertura de la tierra de la ciudad de Moquegua y el pueblo de Samegua de 1955

3. Observando la figura 26 correspondiente al Mapa de uso y cobertura de la tierra de la ciudad de Moquegua y el pueblo de Samegua del año 2018, identificamos las 5 categorías de uso y cobertura de la tierra: "Superficie Artificial”, "Cuerpo Agua", "Yacimiento Arqueológico", "Zona Agrícola” y "Sin/Poca Vegetación”; en el cual vemos que la cobertura "Sin/Poca Vegetación” ocupa mayor superficie en la zona de estudio y la cobertura "Superficie Artificial" ocupa menor superficie en la zona de estudio, confirmándonos con los cálculos 
de área en la tabla 6, donde identificamos que la cobertura "Sin/Poca Vegetación" tiene 6 891,53 hectáreas y la cobertura "Cuerpo Agua" tiene 155.27 hectáreas que representan el 52,21 \% y 1,18 \% mostrados en la figura 30.

\section{Tabla 6}

Categorías de uso y cobertura de la tierra de la ciudad de Moquegua y el pueblo de Samegua de 2018.

\begin{tabular}{lrr}
\hline $\begin{array}{l}\text { Categorías de uso y cobertura de la tierra } \\
\text { de 2018 }\end{array}$ & \multicolumn{2}{c}{ Porcentaje } \\
\hline Cuerpo Agua & 155,27 & 1,18 \\
Yacimiento Arqueológico & 208,63 & 1,58 \\
Superficie Artificial & 1927,72 & 14,60 \\
Zona Agrícola & 4016,85 & 30,43 \\
Sin/Poca Vegetación & 6891,53 & 52,21 \\
Total & $\mathbf{1 3 2 0 0 , 0 0}$ & $\mathbf{1 0 0 , 0 0}$ \\
\hline
\end{tabular}

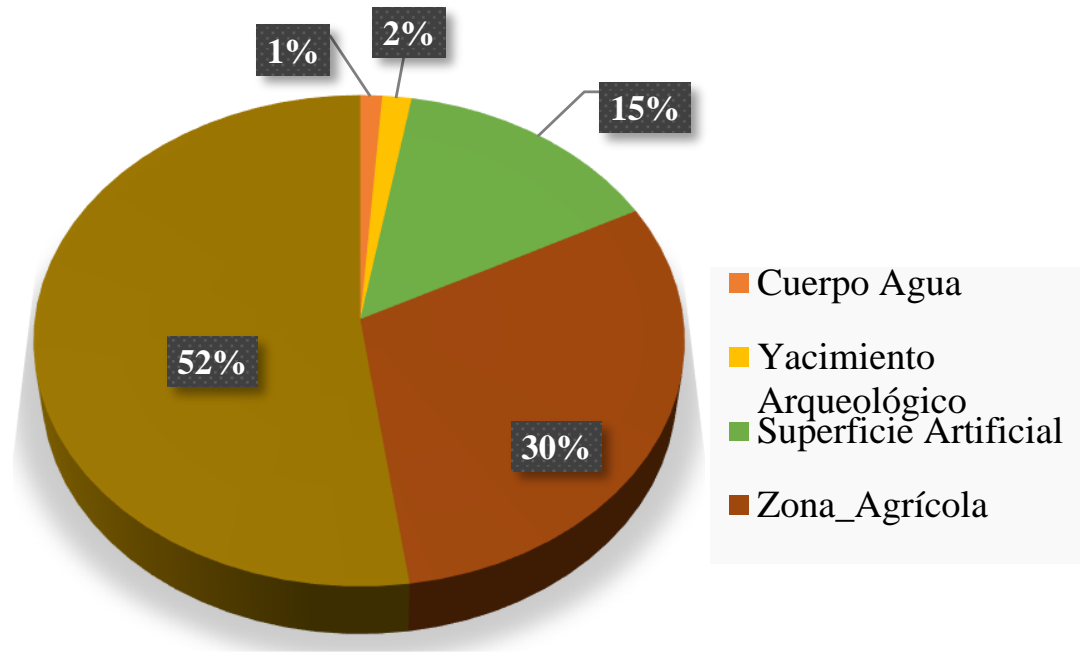

Figura 30. Categorías de uso y cobertura de la tierra de la ciudad de Moquegua y el pueblo de Samegua de 2018.

4. En el mapa de cambios de uso y cobertura de la tierra de la ciudad de Moquegua y el pueblo de Samegua entre 1955 y 2018 de la figura 27, podemos percibir la distribución espacial en 14 zonas que cambiaron de uso y cobertura de la tierra 
y 05 zonas que no cambiaron, correspondientes a: "Superficie Artificial", “Cuerpo Agua”, "Yacimiento Arqueológico", "Zona Agrícola” y "Sin/Poca Vegetación”. Podemos analizar cada uno de los cambios en orden de ocupación de áreas de menor a mayor:

1) De Superficie Artificial a Sin/Poca Vegetación: ocupa 0,67 hectáreas, esta zona ocupaba parte de la carretera antigua de Moquegua a Arequipa.

2) De Cuerpo Agua a Sin/Poca Vegetación: ocupa 0,79 hectáreas, son zonas que antes eran parte del cauce de Rio Tumilaca y por la reducción del cauce en algunos lugares, estas quedaron aisladas de ser parte del cauce.

3) De Yacimiento Arqueológico a Sin/Poca Vegetación: ocupa 1,5 hectáreas, se da en la zona de OMO debido a que se construyó la carretera, y fue segmentada la área arqueológica y parte de ella es ocupada por la cobertura Sin/Poca Vegetación.

4) De Superficie Artificial a Zona Agrícola: ocupa 2,00 hectáreas, estas zonas identificadas resultan de la ocupación de área que antes eran carreteras y fueron ocupadas para ser zonas agrícolas, al momento de ejecutar las vías de la Av, La Paz que conecta desde el Ovalo José Carlos Mariátegui hasta la carretera Moquegua Tacna, también se encuentras las áreas de la vía que une desde el Aeropuerto al Centro Poblado de los Ángeles.

5) De Zona Agrícola a Sin/Poca Vegetación: ocupa 5,54 hectáreas, son zonas pequeñas que se acumulan para formar este grupo, localizadas en la parte baja del valle de Moquegua, probablemente tuvieron escases de agua y optaron por otras zonas agrícolas. 
6) De Cuerpo Agua a Superficie Artificial: ocupa 10,50 hectáreas, es la zona que ocupa actualmente la carretera conocida como el malecón, lo que minimizo el cauce del río.

7) De Sin/Poca Vegetación a Cuerpo Agua: ocupa 10,76 hectáreas, son pequeñas zonas que fueron ocupadas por el cauce del rio y mayormente son zonas donde se construyeron reservorios de agua para cada parcela en las nuevas zonas agrícolas.

8) De Yacimiento Arqueológico a Superficie Artificial: ocupa 14,80 hectáreas, son las áreas que fueron invadidas para construcción de carreteras y viviendas.

9) De Zona Agrícola a Cuerpo Agua: ocupa 16,45 hectáreas, son zonas agrícolas que fueron ocupadas por los ríos durante eventos de inundación y actualmente quedaron como parte del cauce de rio.

10) De Yacimiento Arqueológico a Zona Agrícola: ocupa 43,92 hectáreas, áreas arqueológicas que fueron invadidas con fines agrícolas.

11) De Cuerpo Agua a Zona Agrícola: ocupa 115,59 hectáreas, son zonas de cauce rio que fueron invadidas para la actividad agrícola.

12) De Zona Agrícola a Superficie Artificial: ocupa 246,20 hectáreas, son zonas que fueron ocupadas para la construcción de carreteras y viviendas.

13) De Sin/Poca Vegetación a Superficie Artificial: ocupa 1563,62 hectáreas, que fueron ocupadas por la construcción de carreteras y viviendas.

14) De Sin/Poca Vegetación a Zona Agrícola: es la última zona que tiene 2308,21 hectáreas, que fueron ocupadas por la actividad agrícola.

En el mapa de la figura 27 también observamos categorías que no cambiaron y aún se mantienen, indicamos en orden de ocupación de áreas, de menor a mayor: 
1) Se mantiene Superficie Artificial: ocupa 92,61 hectáreas, que es ocupada por los centros históricos de la ciudad de Moquegua y el pueblo de Samegua, el aeródromo Hernán Turque Podesta, y carreteras.

2) Se mantiene Cuerpo Agua: ocupa 128,06 hectáreas, ocupada únicamente por cauces de los ríos de Moquegua, Torata y Huaracane.

3) Se mantiene Yacimiento Arqueológico: ocupa 208,64 hectáreas, son las zonas que respetaron como patrimonios culturales, recocidos por el Instituto Nacional de Cultura del Perú.

4) Se mantiene Zona Agrícola: ocupa 1547,13 hectáreas, corresponde a la zona agrícola del valle cercana a los ríos.

5) Se mantiene Sin/Poca Vegetación: ocupa 6883,37 hectáreas, son zonas que en su mayoría corresponden a las tierras eriazas del estado.

Las cantidades de áreas y porcentajes de ocupación de las zonas mencionadas se presentan en la tabla 7.

\section{Tabla 7}

Análisis de cambios de uso y cobertura de la tierra de la ciudad de Moquegua y el pueblo de Samegua entre 1955 y 2018

\begin{tabular}{lrr}
\hline Cambio de uso y cobertura de la tierra & $\begin{array}{l}\text { Área } \\
\text { Porcentaje }\end{array}$ & $\begin{array}{l}\text { (h) } \\
\text { De Superficie Artificial a Sin/Poca Vegetación }\end{array}$ \\
\hline De Cuerpo Agua a Sin/Poca Vegetación & 0,67 & 0,005 \\
De Yacimiento Arqueológico a Sin/Poca & & 0,006 \\
Vegetación & 1,15 & 0,009 \\
De Superficie Artificial a Zona Agrícola & 2,00 & 0,015 \\
De Zona Agrícola a Sin/Poca Vegetación & 5,54 & 0,042 \\
De Cuerpo Agua a Superficie Artificial & 10,50 & 0,080 \\
\hline
\end{tabular}




\begin{tabular}{lrr}
\hline De Sin/Poca Vegetación a Cuerpo Agua & 10,76 & 0,081 \\
De Yacimiento Arqueológico a Superficie Artificial & 14,80 & 0,112 \\
De Zona Agrícola a Cuerpo Agua & 16,45 & 0,125 \\
De Yacimiento Arqueológico a Zona Agrícola & 43,92 & 0,333 \\
De Cuerpo Agua a Zona Agrícola & 115,59 & 0,876 \\
De Zona Agrícola a Superficie Artificial & 246,20 & 1,865 \\
De Sin/Poca Vegetación a Superficie Artificial & 1563,62 & 11,846 \\
De Sin/Poca Vegetación a Zona Agrícola & 2308,21 & 17,486 \\
Se mantiene Superficie Artificial & 92,61 & 0,702 \\
Se mantiene Cuerpo Agua & 128,06 & 0,970 \\
Se mantiene Yacimiento Arqueológico & 208,64 & 1,581 \\
Se mantiene Zona Agrícola & 1547,13 & 11,721 \\
Se mantiene Sin/Poca Vegetación & 6883,37 & 52,147 \\
Total & $\mathbf{1 3 ~ 2 0 0 , 0 0}$ & $\mathbf{1 0 0 , 0 0 0}$ \\
\hline
\end{tabular}

La evolución y tasa de variación del uso y cobertura de la tierra de la ciudad de Moquegua y el pueblo de Samegua de 1955 al 2018 se muestra en la tabla 8 y figura 31.

\section{Tabla 8}

Evolución y tasa de variación de uso y cobertura de la tierra de la ciudad de Moquegua y el pueblo de Samegua de 1955 al 2018

\begin{tabular}{|c|c|c|c|c|c|}
\hline \multirow[t]{3}{*}{$\begin{array}{l}\text { Categorías de uso y } \\
\text { cobertura de la tierra }\end{array}$} & \multicolumn{3}{|c|}{ Área en hectáreas (ha) } & \multirow[t]{2}{*}{$\begin{array}{c}\text { Tasa de } \\
\text { variación } \\
(\%)\end{array}$} & \multirow[t]{2}{*}{$\begin{array}{c}\text { Tasa de } \\
\text { variación } \\
\text { (\%/año) }\end{array}$} \\
\hline & & & Cambio & & \\
\hline & 1955 & 2018 & $1955-2018$ & $1955-2018$ & $1955-2018$ \\
\hline Superficie Artificial & 95,28 & 1927,72 & 1832,44 & 1923,22 & 30,53 \\
\hline Cuerpo Agua & 254,95 & 155,27 & $-99,68$ & $-39,10$ & $-0,62$ \\
\hline \multicolumn{6}{|l|}{ Yacimiento } \\
\hline Arqueológico & 268,51 & 208,63 & $-59,88$ & $-22,30$ & $-0,35$ \\
\hline Zona Agrícola & 1815,30 & 4016,85 & 2201,55 & 121,28 & 1,93 \\
\hline Sin/Poca Vegetación & 10765,96 & 6891,53 & $-3874,43$ & $-35,99$ & $-0,57$ \\
\hline
\end{tabular}




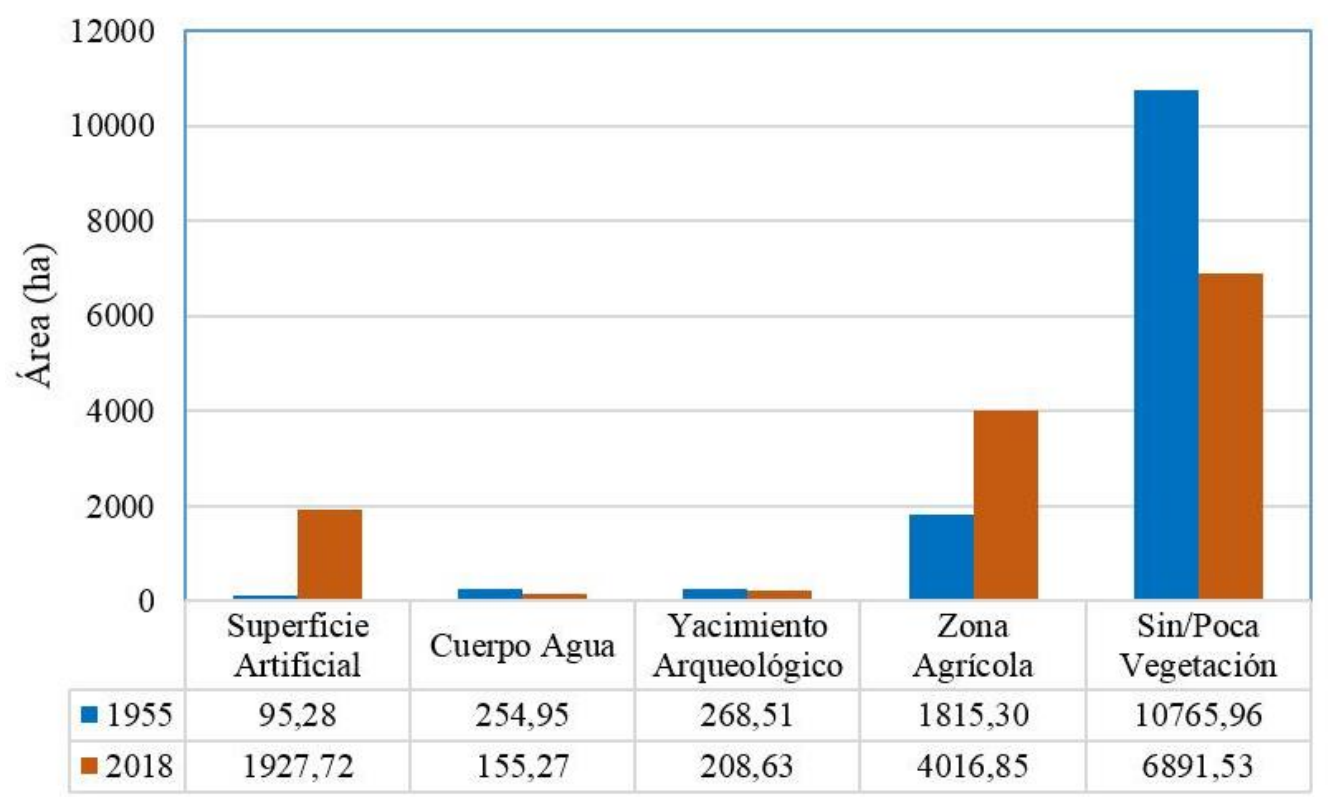

Figura 31. Cambios de uso y cobertura de la tierra de la ciudad de Moquegua y el pueblo de Samegua de 1955 y 2018.

Observando la tabla 8 y figura 31, identificamos que los cambios positivos o aumento de superficie se dan en dos categorías, la Zona Agrícola aumento 2 201,55 hectáreas con una tasa de 1,93 \% por año y la Superficie Artificial aumento 1832,44 hectáreas con una tasa de variación de 30,53 \% por año; mientras que en los cambios negativos o disminución son tres categorías, Yacimiento Arqueológico que disminuyó 59,88 hectáreas con una tasa de variación de -0,35 \% por año, Cuerpo Agua que disminuyó 99,68 hectáreas con una tasa de variación de -0,62 \%/año y la cobertura Sin/Poca Vegetación que disminuyo 3874,33 hectáreas con una tasa de variación de $-0,57 \%$ por año, que también se presenta en la matriz de tabulación cruzada de los mapas de uso y cobertura de la tierra de 1955 y 2018 en la tabla 9 y tabla 10 de la síntesis de uso y cobertura de la tierra de 1955 y 2018 por categoría. 


\section{Tabla 9}

Matriz de tabulación cruzada general de uso y cobertura de la tierra de la ciudad de Moquegua y el pueblo de Samegua de 1955 y 2018

\begin{tabular}{|c|c|c|c|c|c|c|c|}
\hline & \multicolumn{5}{|c|}{ Año 2018} & \multirow{2}{*}{$\begin{array}{c}\text { Total } \\
1955\end{array}$} & \multirow[t]{2}{*}{ Pérdida } \\
\hline & $\begin{array}{l}\text { Superficie } \\
\text { Artificial }\end{array}$ & $\begin{array}{l}\text { Cuerpo } \\
\text { Agua }\end{array}$ & $\begin{array}{l}\text { Yacimiento } \\
\text { Arqueológico }\end{array}$ & $\begin{array}{l}\text { Zona } \\
\text { Agrícola }\end{array}$ & $\begin{array}{l}\text { Sin/Poca } \\
\text { Vegetación }\end{array}$ & & \\
\hline Año 1955 & & & & & & & \\
\hline $\begin{array}{l}\text { Superficie } \\
\text { Artificial }\end{array}$ & 92,61 & 0,00 & 0,00 & 2,00 & 0,67 & 95,28 & 2,67 \\
\hline $\begin{array}{l}\text { Cuerpo Agua } \\
\text { Yacimiento }\end{array}$ & 10,50 & 128,06 & 0,00 & 115,59 & 0,79 & 254,95 & 126,88 \\
\hline $\begin{array}{l}\text { Arqueológico } \\
\text { Zona }\end{array}$ & 14,80 & 0,00 & 208,64 & 43,92 & 1,15 & 268,51 & 59,88 \\
\hline $\begin{array}{l}\text { Agrícola } \\
\text { Sin/Poca }\end{array}$ & 246,20 & 16,45 & 0,00 & 1547,13 & 5,54 & 1815,31 & 268,18 \\
\hline Vegetación & 1563,62 & 10,76 & 0,00 & 2308,21 & 6883,37 & 10765,96 & 3882,59 \\
\hline Total 2018 & 1927,72 & 155,27 & 208,64 & 4016,85 & 6891,53 & & \\
\hline Ganancia & 1835,12 & 27,20 & 0,00 & 2469,72 & 8,16 & & \\
\hline
\end{tabular}

\section{Tabla 10}

Síntesis de uso y cobertura de la tierra de la ciudad de Moquegua y el pueblo de Samegua de 1955 y 2018 .

\begin{tabular}{clrrrr}
\hline $\mathbf{N}^{\circ}$ & Categoría de uso y cobertura & Permanente & Ganancia & Perdida & Cambio Total \\
\hline 1 Superficie Artificial & 92,61 & 1835,12 & 2,67 & 1832,44 \\
2 & Cuerpo Agua & 128,06 & 27,20 & 126,88 & $-99,68$ \\
3 & Yacimiento Arqueológico & 208,64 & 0,00 & 59,88 & $-59,88$ \\
4 & Zona Agrícola & 1547,13 & 2469,72 & 268,18 & 2201,54 \\
5 & Sin/Poca Vegetación & 6883,37 & 8,16 & 3882,59 & $-3874,43$ \\
Total & $\mathbf{8 ~ 8 5 9 , 8 1}$ & $\mathbf{4 3 4 0 , 2 0}$ & $\mathbf{4 3 4 0 , 2 0}$ & \\
\hline
\end{tabular}




\section{CAPÍTULO III}

\section{CONCLUSIONES Y RECOMENDACIONES}

\subsection{Conclusiones}

Primera: Con base en los resultados obtenidos por el empleo de las técnicas de geoprocesamiento para alcanzar los objetivos de esta investigación, se concluye, que las prácticas de uso y cobertura de la tierra en la zona de la ciudad de Moquegua y el pueblo de Samegua se alteraron significativamente en 63 años, este cambio de uso y cobertura de la tierra fue de $33 \%$, donde disminuyeron grandemente las zonas sin o con poca vegetación, que fueron ocupadas en su mayoría por las zonas agrícolas y el área de superficie artificial por causa de la urbanización.

Segunda: A partir del geoprocesamiento de las fotografías aéreas del año 1955, se clasifico en cinco categorías de uso y cobertura de la tierra por la metodología Corine Land Cover, donde el 81 \% (1 0765,96 ha) de la superficie en estudio (13 200 ha) era ocupada por la categoría "Sin/Poca Vegetación", formada por terrenos mayormente naturales, y las cuatro categorías ocupan el $19 \%$ (2 434,04 ha), las mismas que fueron ocupadas de la siguiente manera: categoría "zona agrícola" con 13,75 \% (1 815,30 ha), categoría "Yacimiento Arqueológico" con 2,03\% (268,51 ha), categoría "Cuerpo Agua" con 1,93 \% (254,95 ha) y categoría "Superficie Artificial” que con 0,72 \% (95,28 ha). 
Tercera: Con el geoprocesamiento de las imágenes satelitales de alta resolución de google earth del año 2018, se clasifico de acuerdo a las cinco categorías de uso y cobertura de la tierra del año 1955 por la metodología Corine Land Cover, donde se pudo identificar que el 52,21 $\%$ (6 891,53 ha) de la superficie en estudio (13 200 ha) actualmente es ocupada por la categoría "Sin/Poca Vegetación", son terrenos mayormente naturales, y las demás categorías están ocupadas por la “zona agrícola" con 30,43\% (4 016,85 ha), "Superficie Artificial” con 14,60 \% (1 927,72 ha), "Yacimiento Arqueológico" con 1,58 \% (208,63 ha), y “Cuerpo Agua” con 1,18\% (155,27 ha).

Cuarta: Las técnicas de geoprocesamiento fueron imprescindibles para elaborar la cartografía y la base de datos de cambios de uso y cobertura de la tierra de 1955 y 2018 en la zona de estudio. La matriz de tabulación cruzada propuesta por Pontius et al., (2004) es una metodología importante para este tipo de análisis, que permitió detectar los cambios de aumento, disminución y permanencia en el uso y cobertura de las cinco categorías, Concluyendo que la cobertura que tuvo mayor aumento es “Zona Agrícola” aumento 2 469,72 hectáreas, sumadas al área de permanencia de 1547.13 hectáreas tiene 4 016,85 hectáreas y seguida de la cobertura "Superficie Artificial" por el aumento de 1 835,12 hectáreas, sumadas a las zonas de permanencia de 92,61 hectáreas, actualmente tiene 1927,72 ha. Cabe resaltar que el cuerpo de agua tiene una pérdida de 126,88 ha, por la ocupación de la "Zona Agrícola" en 115,59 ha y la "Área Artificial" en 10,50 ha que corresponde a la construcción de la vía el malecón principalmente. La mayor tasa de variación es la de "Superficie Artificial" que tuvo un incremento anual de 30,53 \%, seguida de la "Zona Agrícola" que tuvo un incremento de $1,93 \%$ por año. 


\subsection{Recomendaciones}

Primera: Se recomienda a las autoridades locales, regionales y nacionales que deban proteger las áreas de protección ambiental y/o conservación de los restos o áreas arqueológicas de acuerdo a las normativas vigentes, como la regulación de las fajas marginales de ríos que no deberían estar ocupadas por "Zonas Agrícolas" ni "Superficie Artificial” (viviendas, carreteras, canales de riego entre otros) convirtiéndose en zonas de alto riesgo propensas a inundaciones; por lo que se debe tener en consideración los resultados encontrados en este trabajo académico, para las tomas de decisión en los planes de gobierno para el ordenamiento territorial y ambiental de la Ciudad de Moquegua y el pueblo de Samegua, así como aplicar esta metodología en otros lugares.

Segunda: Se recomienda que la Universidad José Carlos Mariátegui debe implementar asignaturas como el curso Geoprocesamiento, Geoestadística ambiental, fotogrametría y teledetección o percepción remota para los estudios de monitoreamiento ambiental, ordenamiento territorial, gestión ambiental entre otros afines, utilizando imágenes Landsat y PeruSat hasta el uso de imágenes de drones.

Tercera: Recomendamos utilizar la metodología de Pontius et al., (2004), cuando realicen estudios de cambio de uso y cobertura de la tierra, que son fundamentales para el ordenamiento territorial y ambiental de un espacio geográfico. 


\section{REFERENCIAS BIBLIOGRÁFICAS}

A, D., Zhao, W., Qu, X., Jing, R., \& Xiong, K. (2016). Spatio-temporal variation of vegetation coverage and its response to climate change in North China plain in the last 33 years. International Journal of Applied Earth Observation and Geoinformation, 53, 103-117. https://doi.org/10.1016/J.JAG.2016.08.008

Arnillas, C. ., Barrena, V., Llactayo, W., Ortíz, H., Regal, F., Rubín de Celis, E., ... Vásquez, R. (2014). Informe Final del Proyecto: Análisis de las Dinámicas de Cambio de Cobertura de la Tierra en la Comunidad Andina. Lima. Recuperado de http://www.minam.gob.pe/ordenamientoterritorial/wpcontent/uploads/sites/18/2013/10/Informe-final-de-Proyecto-Dinamica-delos-Cambios-de-la-Tierra-CAN.pdf

Avalos, P. K. (2012). Percepción Remota Y Sus Aplicaciones a La Evaluación De La Calidad Del Agua. Universidad Nacional Autónoma de México. Recuperado de http://www.ptolomeo.unam.mx:8080/xmlui/bitstream/handle/132.248.52.100 /2409/Tesis.pdf?sequence $=1$

Batista, F. (2011). Land Function: origin and evolution of the concept. Cadernos Curso De Doutoramento Em Geografia Flup, 67-92. Recuperado de http://ler.letras.up.pt/uploads/ficheiros/9130.pdf

Bonfim, F. C. G., Cordeiro, P. H. C., Peres, C. A., Canale, G. R., \& Bernardo, C. S. S. (2018). Combining modeling tools to identify conservation priority areas: A case study of the last large-bodied avian frugivore in the Atlantic Forest. Global and Ecology Conservation. https://doi.org/10.1016/j.gecco.2018.e00426

Bovet, J., Reese, M., \& Köck, W. (2018). Taming expansive land use dynamics Sustainable land use regulation and urban sprawl in a comparative perspective. Land Use Policy, 77, 837-845. https://doi.org/10.1016/J.LANDUSEPOL.2017.03.024

Briassoulis, H. (2000). Analysis of Land Use Change: Theoretical and Modeling Approaches. Recuperado 19 de octubre de 2018, de http://www.rri.wvu.edu/WebBook/Briassoulis/contents.htm

Buffara, A. A. F. (2018). Iniciando em Geoprocessamento. Curitiba. Recuperado 
de https://docs.ufpr.br/ felipe/sig.pdf

Butler, M. J. A., LeBlanc, C., Belbin, J. A., \& MacNeill, J. L. (1990). Cartografía de recursos marinos: un manual de introducción. FAO Documento Técnico de Pesca (Vol. 274). FAO. https://doi.org/T0390/S

Cabral, A. I. R., \& Costa, F. L. (2017). Land cover changes and landscape pattern dynamics in Senegal and Guinea Bissau borderland. Applied Geography, 82, 115-128. https://doi.org/10.1016/J.APGEOG.2017.03.010

Câmara, G., Casanova, M. A., Hemerly, A. S., Magalhães, G. C., \& Medeiros, C. M. B. (1996). Anatomia de Sistemas de Informação Geográfica. 1996, p. 205. Recuperado de http://www.dpi.inpe.br/gilberto/livro/anatomia.pdf

Câmara, G., Davis, C., \& Vieira, M. A. M. (2018). Introdução à Geoinformática. Sao Jose dos campos. Recuperado de http://www.dpi.inpe.br/gilberto/livro/introd/index.html

Commisison européenne. (1994). CORINE land cover. Technical guide. EUR 12585 EN. Environment, nuclear safety and civil protection series. Luxembourg: Office for Official Publications of the European Communities.

CORINE Land cover. (1994). CORINE Land cover - Part 1: Methodology European Environment Agency. Recuperado 12 de diciembre de 2018, de https://www.eea.europa.eu/publications/COR0-part1

CORINE Land Cover. (2018). CORINE Land Cover. Recuperado 1 de noviembre de 2018, de https://land.copernicus.eu/pan-european/corine-land-cover

Cuentas, T. O. (2017). Análise Espaço Temporal da Bacia Hidrográfica do Alto do Rio Moquega no Peru| PPGM - Programa de Pós-Graduação em Modelagem em Ciências da Terra e do Ambiente. Universidade Estadual de Feira de Santana. Recuperado de http://www2.uefs.br:8081/ppgm/análise-espaçotemporal-da-bacia-hidrográfica-do-alto-do-rio-moquega-no-peru

D.R. N ${ }^{\circ}$ 002-2018-GR/MOQ. Aprueban el Reglamento Interno de la Comisión Técnica Regional de Zonificación Ecológica y Económica de la Región Moquegua, El Peruano $§ \quad$ (2018). Perú. Recuperado de https://busquedas.elperuano.pe/normaslegales/aprueban-el-reglamentointerno-de-la-comision-tecnica-region-decreto-no-002-2018-grmoq$1692400-1 /$ 
Daels, L. (1992). Aerial Photographs and Satellite Images as an Archives (Information Power in Horizontal and Vertical Sense). En J. R. L. Editor(s): Lawrence W. Fritz (Ed.), XVIIth ISPRS Congress Technical Commission VI: Economic, Professional and Eductional Apsects of Photogrammetry and Remote Sensing (pp. 113-119). Belgium: August 2-14, 1992, Washington, D.C., USA. Recuperado de http://www.isprs.org/proceedings/XXIX/congress/part6/113_XXIX-part6.pdf Deng, J. S., Wang, K., Hong, Y., \& Qi, J. G. (2009). Spatio-temporal dynamics and evolution of land use change and landscape pattern in response to rapid urbanization. Landscape and Urban Planning, 92(3-4), 187-198. https://doi.org/10.1016/J.LANDURBPLAN.2009.05.001

Di Gregorio, A., \& Jansen, L. J. M. (2000). Land cover classification system : LCCS : classification concepts and user manual. Food and Agriculture Organization of the United Nations. Recuperado de http://www.fao.org/docrep/003/x0596e/X0596e00.htm\#P-1_0

ESRI. (2018). World Imagery (WGS84). Recuperado 28 de octubre de 2018, de http://www.arcgis.com/home/item.html?id=898f58f2ee824b3c97bae0698563 $\mathrm{a} 4 \mathrm{~b} 3$

Facco, D. S., Benedetti, A. C., Kaiser, E. A., \& Pereira, F. W. (2017). Avaliação da dinâmica do uso e cobertura da terra no município de Faxinal do Soturno no estado do Rio Grande do Sul. En Os Desafios da Geografia Física na Fronteira do Conhecimento (pp. 6846-6855). INSTITUTO DE GEOCIÊNCIAS - UNICAMP. https://doi.org/10.20396/sbgfa.v1i2017.1876

FAO. (1995). Planning for sustainable use of land resources; towards a new approach. 2009 IEEE Pacific Rim Conference on Communications, Computers and Signal Processing. Food and Agriculture Organization of the United Nations. https://doi.org/10.1109/PACRIM.2009.5291415

FAO. (2001). Indicadores de la calidad de la tierra y su uso para la agricultura sostenible y el desarrollo rural. (Organizaci). Organización de las Naciones Unidas para la Agricultura y la Alimentación. Recuperado de http://www.fao.org/docrep/004/W4745S/w4745s00.htm\#toc

Gamarra, A. S. E. (2017). Análisis de la cobertura y uso de la tierra utilizando 
imágenes de resolución espacial media para el distrito de San Ramón Chanchamayo - Junín - Perú. Recuperado de http://repositorio.lamolina.edu.pe/handle/UNALM/3292

Gao, G., Shen, Q., Zhang, Y., Pan, N., Ma, Y., Jiang, X., \& Fu, B. (2018). Determining spatio-temporal variations of ecological water consumption by natural oases for sustainable water resources allocation in a hyper-arid endorheic basin. Journal of Cleaner Production, 185, 1-13. https://doi.org/10.1016/j.jclepro.2018.03.025

Gao, L., Hou, B., Cai, M. L., Zhai, J. J., Li, W. H., \& Peng, C. L. (2018). General laws of biological invasion based on the sampling of invasive plants in China and the United States. Global Ecology and Conservation, e00448. https://doi.org/10.1016/J.GECCO.2018.E00448

ICA, I. C. A. (2018). Mission International Cartographic Association. Recuperado 31 de octubre de 2018, de https://icaci.org/mission/

INEGI. (2005). Guía para la Interpretación de Cartografía Fotografía Aérea. (I. N. de Estadística \& G. e Informática, Eds.). México. Recuperado de www.inegi.gob.mxatención,usuarios@inegi.gob.mx

INEI, I. N. de E. e I. (2018a). Directorio Nacional de Municipalidades Provinciales, Distritales y de Centros Poblados 2018. (I. N. de E. e Informática, Ed.). Lima. Recuperado de www.inei.gob.pe

INEI, I. N. de E. e I. (2018b). Perú: Crecimiento y distribución de la población, 2017 Primeros Resultados. Lima. Recuperado de https://www.inei.gob.pe/media/MenuRecursivo/publicaciones_digitales/Est/ Lib1530/libro.pdf

Kuon, C. L. E. (1996). Retazos de la historia de Samegua. (Municipalidad Distrital de Samegua, Ed.). Moquegua. Recuperado de http://www.luiskuoncabello.com/uploads/7/4/5/5/74552227/retazos_de_la_hi storia_de_samegua_v.1.pdf

Lambin, E. F., Rounsevell, M. D. A., \& Geist, H. J. (2000). Are agricultural landuse models able to predict changes in land-use intensity? Agriculture, Ecosystems and Environment, 32(1-3), 321-331. https://doi.org/10.1016/S0167-8809(00)00235-8 
Lao, R. B., \& Peláez, H. D. (1988). La teledetección y los Sistemas de Información Geográfica para el manejo de las tierras. Revista Ciencias Técnicas Agropecuarias, 27(1), 54-65. Recuperado de http://scielo.sld.cu/scielo.php?script=sci_arttext\&pid=S207100542018000100006

León, Y. (2002). Introducción a las Imágenes Satelitales. (Centro de Investigaciones Geoespaciales (CIG), Ed.). Santo Domingo. Recuperado de http://percepcion-remota.intec.edu.do/Material de apoyo sensores remotos.pdf López, A. A., Escolano, C. L., Solé, C. S., Antón, M. Z., Llovería, R. M., \& Campos, Á. P. (2013). El potencial de Google Earth aplicado al análisis espacial en geografía. En Innovación en la enseñanza de la geografía ante los desafios sociales y territoriales (pp. 179-194). Recuperado de https://ifc.dpz.es/recursos/publicaciones/33/36/10arranzetal.pdf

Macedo, R. de C., Filho, A. L. S., Farley, J. C., Fantini, A. C., Cazella, A. A., \& Sinisgalli, P. A. de A. (2018). Land use and land cover mapping in detailed scale: A case study in Santa Rosa de Lima-SC. Boletim de Ciencias Geodesicas, 24(2), 217-234. https://doi.org/10.1590/S198221702018000200015

Malarvizhi, K., Kumar, S. V., \& Porchelvan, P. (2016). Use of High Resolution Google Earth Satellite Imagery in Landuse Map Preparation for Urban Related Applications. $\quad$ Procedia Technology, 24, 1835-1842. https://doi.org/10.1016/j.protcy.2016.05.231

Moquegua Noticias. (2012). Emergencia en Moquegua por intentas lluvias y entradas de grandes volúmenes de huaycos. Recuperado 26 de octubre de 2018, de https://www.moqueguanoticias.com/emergencia-en-moquegua-porintentas-lluvias-y-entradas-de-grandes-volumenes-de-huaycos.html

MPMN, M. P. de M. N. (2016). Plan de desarrollo urbano sostenible MoqueguaSamegua 2016-2026 Resumen Ejecutivo. Moquegua. Recuperado de http://www.munimoquegua.gob.pe/sites/default/files/archivos/pb/resumen_ej ecutivo_plan_de_desarrollo_urbano_moquegua_samegua_20162026_opt.pdf

MPMN, M. P. de M. N. (2018). Plan de desarrollo urbano sostenible Moquegua- 
Samegua, 2016-2026 Volumen II. Recuperado de www.munimoquegua.gob.pe

Mucova, S. A. R., Filho, W. L., Azeiteiro, U. M., \& Pereira, M. J. (2018). Assessment of land use and land cover changes from 1979 to 2017 and biodiversity \& land management approach in Quirimbas National Park, Northern Mozambique, Africa. Global Ecology and Conservation, 16, e00447. https://doi.org/https://doi.org/10.1016/j.gecco.2018.e00447

Murillo, S. A. (2018). Análisis de cambio de cobertura y uso actual de la tierra con imágenes satelitales del distrito de Llacanaora periodo 2001 - 2016. Universidad Nacional de Cajamarca. Recuperado de http://renati.sunedu.gob.pe/handle/sunedu/230568

Nantel, P. L., Jones, J., \& Drake, C. (2018). Viability of multiple populations across the range of a species at risk: The case of Pitcher's thistle, Cirsium pitcheri, in Canada. Global Ecology and Conservation. https://doi.org/10.1016/j.gecco.2018.e00445

Natural Resources. (1999). Fundamentals of Remote Sensing. Forestry, (November), 258. https://doi.org/10.1016/0191-8141(93)90072-I

Nkeki, F. N. (2016). Spatio-temporal analysis of land use transition and urban growth characterization in Benin metropolitan region, Nigeria. Remote Sensing Applications: Society and Environment, 4, 119-137. https://doi.org/10.1016/J.RSASE.2016.08.002

Oblitas, V. C. T. (2018). Determinación de cambio de cobertura 2001 - 2013 del bosque tropical estacionalmente seco de la cuenca Amojú - Jaén, utilizando imágenes satelitales. Universidad Nacional de Cajamarca. Recuperado de http://renati.sunedu.gob.pe/handle/sunedu/225669

Patiño, M., \& Tobasura, I. (2011). Tomadores de decisión en sistemas ganaderos de la cuenca alta del río Guarinó (Caldas, Colombia): percepción de problemas ambientales y prácticas de conservación del agua. Revista Luna Azul, (33), 97109. Recuperado de http://www.scielo.org.co/pdf/luaz/n33/n33a09.pdf

Pina, M. de F., \& Santos, S. M. (2018). Conceitos básicos de Sistemas de Informação Geográfica e Cartografia aplicados à saúde. Brasilia. Recuperado de http://www.bvsde.paho.org/cursode/fulltext/Livro_cartog_SIG_saude.pdf 
Poggi, F., Firmino, A., \& Amado, M. (2018). Planning renewable energy in rural areas: Impacts on occupation and land use. Energy, 155, 630-640. https://doi.org/10.1016/J.ENERGY.2018.05.009

Pontius, R. G., Shusas, E., \& Mceachern, M. (2004). Detecting important categorical land changes while accounting for persistence. Agriculture, Ecosystems and Environment, 101, 251-268. https://doi.org/10.1016/j.agee.2003.09.008

Posada, E., \& Salvatierra, C. (2016). Análisis comparativo de las metodologías de los sistemas de clasificación de la cobertura de la Tierra LCCS y CORINE, para mapeo de coberturas terrestres. Revista Geográfica. Recuperado de https://web.a.ebscohost.com/abstract?direct=true\&profile=ehost\&scope=site \&authtype $=$ crawler $\&$ jrnl $=05566630 \& A N=130775817 \& \mathrm{~h}=\mathrm{LpbEj} 8 \mathrm{zvKGtkU}$ M85HRiqZzV3PAOz0\%2FNu2Mdp0ujbftSvkWX5wBmRQwUES\%2BxsY HpVL6QCp7Kmw9mehgTCPGrW8A\%3D\%3D\&crl=c\&resultNs=AdminW ebAuth\&resultLoca

R.M. N 081-2016-MINAM. (2016). Procedimiento Técnico y Metodológico para la Elaboración del «Estudio Especializado de Análisis de los Cambios de la Cobertura y Uso de la Tierra». En Procedimiento Técnico y Metodológico para la Elaboración del «Estudio Especializado de Análisis de los Cambios de la Cobertura y Uso de la Tierra» (p. 46). Lima. Recuperado de http://geoservidor.minam.gob.pe/intro/monitoreo/cobertura-v-

R.M. $N^{\circ}$ 135-2013-MINAM. Guía metodológica para la elaboración de los instrumentos técnicos sustentatorios para el Ordenamiento Territorial, Pub. L. No. 03-05-2013, Ministerio del Ambiente 20 (2013). Perú: Diario Oficial El Peruano. Recuperado de http://www.minam.gob.pe/wpcontent/uploads/2014/02/rm_135-2013-minam.pdf

Rukundo, E., Liu, S., Dong, Y., Rutebuka, E., Asamoah, E. F., Xu, J., \& Wu, X. (2018). Spatio-temporal dynamics of critical ecosystem services in response to agricultural expansion in Rwanda, East Africa. Ecological Indicators, 89, 696-705. https://doi.org/10.1016/J.ECOLIND.2018.02.032

Sahagún, F. J., \& Reyes, H. (2017). impactos por cambio de uso de suelo en las areas protegidas. CienciaUAT, 12(2), 6-21. Recuperado de 
http://www.scielo.org.mx/scielo.php?script=sci_arttext\&pid=S2007$78582018000100006 \& \operatorname{lng}=\mathrm{es} \& n r m=i s o \&$ tlng=es

Schweitzer, A. M. S., \& Farinelli, M. L. R. (2014). Análisis de cambios de uso del suelo en la Delegación Municipal de Ingeniero White (Buenos Aires, Argentina): aplicación de geotecnologías. Cuadernos de Geografía: Revista Colombiana de Geografía, 23(1), 133-146. https://doi.org/10.1007/s13398014-0173-7.2

Servicio Nacional de Meteorologia e Hidrologia del Perú - SENAMHI. (2010). Guía Climática Turística. (Servicio Nacional de Meteorologia e Hidrologia del Perú - SENAMHI, Ed.) (1. ${ }^{\mathrm{a}}$ ed.). Lima. Recuperado de https://www.senamhi.gob.pe/load/file/01401SENA-20.pdf

Simsek Kiper, P. O., Saito, H., Gori, F., Unger, S., Hesse, E., Yamana, K., ... Baron, R. (2016). Cortical-Bone Fragility - Insights from sFRP4 Deficiency in Pyle's Disease. New England Journal of Medicine, 374(26), 2553-2562. https://doi.org/10.1056/NEJMoa1509342

Simwanda, M., \& Murayama, Y. (2018). Spatiotemporal patterns of urban land use change in the rapidly growing city of Lusaka, Zambia: Implications for sustainable urban development. Sustainable Cities and Society, 39, 262-274. https://doi.org/10.1016/J.SCS.2018.01.039

Soncco, Y., \& Vela, J. (2018). Peligros Geológicos en la Quebrada el Cementerio. Moquegua. Recuperado de http://geocatmin.ingemmet.gob.pe/geocatmin/

Sun, X., Crittenden, J. C., Li, F., Lu, Z., \& Dou, X. (2018). Urban expansion simulation and the spatio-temporal changes of ecosystem services, a case study in Atlanta Metropolitan area, USA. Science of The Total Environment, 622623, 974-987. https://doi.org/10.1016/J.SCITOTENV.2017.12.062

Turner II, B. L., Ross, R. H., \& Skole, D. L. (1993). Relating land use and global land cover change. Recuperado de http://ciesin.org/docs/008-105/008105.html

Turner II, B. L., Skole, D., Sanderson, S., Fischer, G., Fresco, L., \& Leemans, R. (1995). Land-Use and Land-Cover Change Science / Research Plan. IGBP \& HDP (Vol. 35 \& 7). https://doi.org/10.1623/hysj.2005.50.6.1069

United Nations General Assembly. (1994). Elaboration of an international 
convention to combat desertification in countries experiencing serious drought and/or desertification, particularly in Africa. https://doi.org/Accessed online: http://www.unccd.int/convention/menu.php

UNSA, U. N. de S. A., \& INDECI, I. N. de D. C. (2001). Evaluación de peligros de la ciudad de Moquegua. Arequipa. Recuperado de http://sigrid.cenepred.gob.pe/sigridv3/storage/biblioteca//4401_evaluacionde-peligros-de-la-ciudad-de-moquegua.pdf

Valentina, S. M., \& Matar, de S. M. A. (2016). Nociones sobre teledetección. San Juan: Universidad Nacional de San Juan. Recuperado de http://www.unsj.edu.ar/unsjVirtual/cartografiaaplicadaminas/wpcontent/uploads/2016/10/Apuntes-de-cátedra-para-Cartografía-Aplicada.pdf

Valentini, L. (2011). Google Earth-an introduction. Recuperado de http://geomatica.como.polimi.it/corsi/internetGIS/google_earth_2011.pdf

Vilchez, O. M. H. (2018). Análisis de cambio de cobertura y uso de tierra del distrito Chetilla, periodo 1990-2003-2016. Universidad Nacional de Cajamarca. Recuperado de http://renati.sunedu.gob.pe/handle/sunedu/230566

Woldesenbet, T. A., Elagib, N. A., Ribbe, L., \& Heinrich, J. (2018). Catchment response to climate and land use changes in the Upper Blue Nile sub-basins, Ethiopia. Science of The Total Environment, 644, 193-206. https://doi.org/10.1016/J.SCITOTENV.2018.06.198

Yuan, M., \& Bothwell, J. (2013). Space-Time Analytics for Spatial Dynamics. En Integrated Information and Computing Systems for Natural, Spatial, and Social Sciences (p. 15). Oklahoma. https://doi.org/10.4018/978-1-4666-21909.ch017

Zhang, H., Qi, Z., Ye, X., Cai, Y., Ma, W., \& Chen, M. (2013). Analysis of land use/land cover change, population shift, and their effects on spatiotemporal patterns of urban heat islands in metropolitan Shanghai, China. Applied Geography, 44, 121-133. https://doi.org/10.1016/J.APGEOG.2013.07.021 